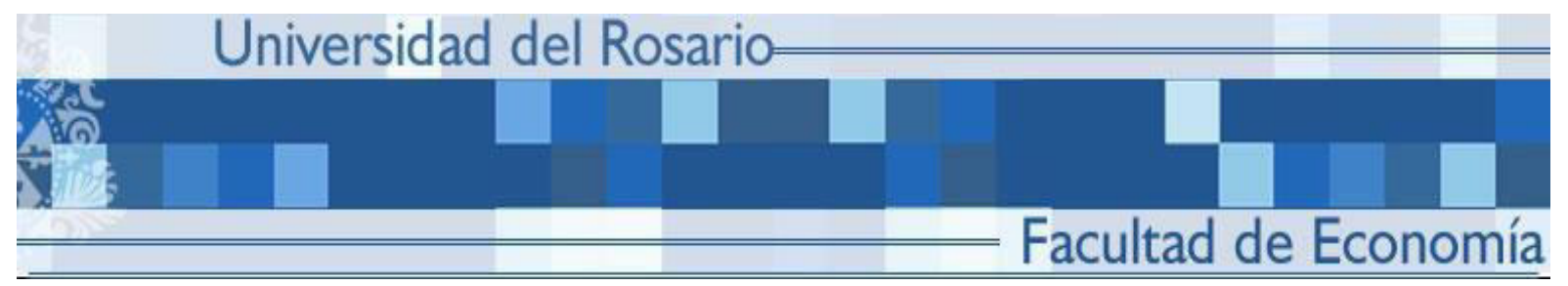

Análisis empírico de los efectos económicos de la colusión:
lecciones para Colombia

Jorge Flórez Acosta

Karoll Gómez Portilla

No. 204

Agosto de 2017 


\title{
Análisis empírico de los efectos económicos de la colusión: lecciones para Colombia
}

\author{
Jorge Flórez Acosta* \\ Universidad del Rosario \\ Karoll Gómez Portilla ${ }^{\dagger}$ \\ Universidad Nacional de Colombia
}

\begin{abstract}
Resumen
En este artículo se revisa uno de los casos más recientes sancionados por la Superintendencia de Industria y Comercio en Colombia: el caso del mercado de pañales desechables para bebé, para a la luz de los métodos y modelos más avanzados que ha desarrollado la literatura económica determinar, de manera rigurosa y precisa, la existencia de la conducta colusiva, qué tan exitosa fue la coordinación entre las empresas del cártel y qué impacto generó tal práctica sobre el mercado. Los resultados permiten concluir que, dada la estructura de oferta actual, la industria presenta resultados que se acercan más a un referente competitivo que a los resultados que obtendrían empresas con alto poder y dominio de mercado.
\end{abstract}

Palabras clave: Colusión, carteles, poder de mercado, estimación estructural de oferta y demanda. Códigos JEL: L1, L4, L6, C3.

*Profesor, Facultad de Economía, Universidad del Rosario. Dirección postal: Calle 12C No. 4-59, Bogotá, Colombia. Dirección electrónica: jorge.florez@urosario.edu.co.

${ }^{\dagger}$ Profesora, Departamento de Economía, Facultad de Ciencias Económicas, Universidad Nacional de Colombia - sede Bogotá. Dirección postal: Carrera 30 No. 45-03, Bogotá, Colombia. Dirección electrónica: kgomezp@unal.edu.co.

Agradecemos a Sergio Rivera Díaz por su colaboración como asistente de investigación. 


\section{Introducción}

En los últimos años, el número de casos de acuerdos restrictivos de la competencia que la Superintendencia de Industria y Comercio (SIC) ${ }^{1}$ ha investigado y sancionado, ha aumentado considerablemente. Entre 2010 y 2016 se han emitido al menos 12 resoluciones sancionatorias por acuerdos entre empresas. Entre ellos, los más frecuentes son los de formación de carteles para la fijación de precios o la manipulación del mercado, con multas impuestas que suman cerca de 800 mil millones de pesos. Entre estos casos, los más representativos son los de cartelización en los sectores de ingenios azucareros ("Caso azúcar"), el de pañales para bebé ("Caso pañales") y el de papel higiénico ("Caso papeles suaves"). ${ }^{2}$ Esta mayor actividad y eficacia se debe, en gran parte, a los importantes cambios que introdujo la Ley 1340 de 2009, que permitieron a la SIC investigar y combatir de forma efectiva la colusión. ${ }^{3}$ Entre tales cambios, se destaca el Programa de beneficios por colaboración que permite a la SIC otorgar una reducción parcial o total de la multa a aquellos agentes (naturales o jurídicos) que contribuyan efectivamente con la investigación de un caso. Tal programa ha favorecido el avance rápido y eficaz de las investigaciones pues ha motivado denuncias y la presentación de pruebas contundentes (como correos electrónicos, grabaciones, declaraciones de funcionarios de las empresas involucradas en el acuerdo, etc.).

Los resultados que ha tenido la SIC en el plano jurídico gracias a la contundencia de las pruebas documentales recolectadas, contrastan con los deficientes análisis económicos que soportan sus decisiones y su uso inadecuado. En efecto, es común encontrar en los "informes motivados" 4 de los casos de cartelización producidos por la SIC dos estrategias que buscan demostrar la existencia de la conducta anticompetitiva: por un lado, se expone todo el material testimonial y documental, y por el otro, se presenta un análisis económico que busca demostrar la existencia del cártel a través del estudio de series de precios en el período en el que el cartel investigado tuvo lugar. Estos análisis han sido utilizados como evidencia para probar la existencia y materialización de las conductas colusivas.

Por ejemplo, en el informe motivado del "Caso pañales" la SIC utilizando técnicas descriptivas como graficar las series de precios y un precio promedio ponderado, argumenta que "[...] los precios de los pañales presentaron una relativa estabilidad en todo el período de análisis" (p. 220). Adicionalmente, con base en el estudio de las series por componentes, la SIC infiere que "[...] las probabilidades de las variaciones del componente cíclico son iguales o muy similares, esto es un indicio concreto de la existencia de coordinación en las decisiones de precios" (p. 222). Finalmente, y después de dedicar tres páginas al análisis de las series de precios de los pañales producidos por las cuatro empresas más grandes de la industria (Kim-

\footnotetext{
${ }^{1}$ Agencia gubernamental encargada de la promoción de la competencia y la protección de los consumidores en Colombia.

${ }^{2}$ En estos tres casos se han impuesto las multas más altas de la historia de este tipo de sanciones: en el primero se impuso una multa total de 216,8 mil millones de pesos, en el segundo una multa de 206,8 miles de millones de pesos y, en el tercero, una multa de 183,4 mil millones de pesos.

${ }^{3}$ En Economía, la colusión hace referencia en sentido estricto al resultado según el cual el equilibrio de mercado se alcanza con unos precios más altos que un referente competitivo, y no al acuerdo que permitió llegar a tal resultado. Sin embargo, en el lenguaje de la política de la competencia es ahora común referirse indistintamente al acuerdo explícito entre empresas para alcanzar el resultado colusivo como cartel o colusión. A lo largo de este artículo, adoptaremos esta última terminología.

${ }^{4}$ Un "informe motivado" es un documento que contiene los resultados de la investigación que se abre cuando la SIC encuentra suficientes motivos para ahondar en un caso. Éste documento contiene análisis documentales, económicos y testimonios de personas involucradas, con el propósito de probar la conducta imputada.
} 
berly, Tecnoquímicas, Familia y Drypers) en el período 2005-2014, la SIC concluye: “[...] la evidencia presentada en este análisis denota que se presenta una baja variabilidad del precio de los pañales para bebé, ..., lo que a su vez podría sugerir la presencia de coordinación en el comportamiento de las decisiones de precio de los investigados que, en este caso, sumado a la prueba directa recogida, corrobora la existencia y ejecución del acuerdo de precios imputado." (p. 222).

Sin embargo, usados para tal propósito, los análisis económicos de la SIC presentan al menos dos problemas: por un lado, la simplicidad, poca profundidad y falta de rigurosidad no se compaginan con las conclusiones que de ellos derivan, y a menudo fallan en mostrar la materialización del cartel en cuestión y cuantificar sus efectos en el mercado. Por otro lado, según la teoría de la política de la competencia, la decisión de sancionar una práctica colusiva debe basarse exclusivamente en pruebas contundentes o directas (documentos y testimonios) y no en especulaciones o estudios del mercado (Motta, 2004). En efecto, la teoría económica y la evidencia internacional han demostrado que los estudios de mercado basados en métodos descriptivos no son prueba suficiente de acuerdos colusivos debido a que, entre otras razones, no es posible identificar separadamente la parte que se debe a las presuntas prácticas colusivas de otros determinantes de mercado como el tamaño del mercado, la existencia de costos y choques comunes, ${ }^{5}$ el estado de la economía, etc. En especial, las conclusiones basadas en análisis de series de precios que reportan estabilidad, niveles de precios "altos" y similitud en los precios de varias empresas rivales durante un período determinado de tiempo (fenómeno conocido como paralelismo de precios), ha sido ampliamente documentado como uno de los métodos que inducen a conclusiones equivocadas a las autoridades de competencia (Motta, 2004).

En consecuencia, ¿Debería la autoridad de competencia omitir cualquier análisis económico y limitarse a recolectar pruebas directas para demostrar y sancionar la existencia de un cartel? La respuesta es No. Los análisis económicos son esenciales para determinar la magnitud del daño. En el caso colombiano la valoración del daño es indispensable para determinar y justificar el monto de la multa que se impondrá a las empresas involucradas en la conducta colusiva, tal como lo manda el artículo 25 de la Ley 1340 de 2009. ${ }^{6}$ La literatura económica ofrece un menú de métodos y herramientas que pueden ser utilizadas para hacer análisis rigurosos y completos de detección de prácticas colusivas, y de cuantificación de sus impactos en el mercado. Estos se pueden clasificar en dos categorías: modelos en forma reducida y modelos estructurales. ${ }^{7}$ Estos métodos no son excluyentes. Aunque la modelación estructural

\footnotetext{
${ }^{5}$ Ejemplos de estos choques son: aumentos en el precio de los insumos, inflación o devaluación de la tasa de cambio.

${ }^{6}$ La Ley contempla como uno de los criterios para "graduar" el monto de la multa a imponer a los infractores "el impacto que la conducta tenga sobre el mercado".

${ }^{7}$ Los modelos estructurales se basan en la postulación de un modelo teórico riguroso en el cual los agentes maximizan funciones de utilidad y beneficios incluyendo una perturbación aleatoria que tiene una interpretación económica (o estructural) en el contexto del modelo. De éste, se derivan las ecuaciones que, con ayuda de datos, servirán para estimar los parámetros del modelo. En contraste, la modelación en forma reducida analiza correlaciones condicionales que son parcialmente consistentes con la teoría mediante la especificación de modelos casi siempre lineales y paramétricos. Ambos métodos se mantienen vigentes y son útiles para hacer análisis empíricos de mercados bajo colusión, aunque hay un trade-off entre alcances del método y costos. Los modelos estructurales permiten simular equilibrios alternativos al estimado (técnicamente conocidos como "contrafactuales") y hacer análisis de estática comparativa, mientras que los modelos en forma reducida permiten determinar correlaciones entre variables y, a lo sumo, relaciones causales entre variables. Sin embargo, la modelación estructural implica costos como la complejidad en la estimación por generar ecuaciones general-
} 
es mucho más completa. requiere más y mejor información, e implica mayor complejidad en el análisis, constituye un complemento clave de cualquier análisis en forma reducida e incrementa considerablemente el alcance de los análisis descriptivos, al permitir la simulación de escenarios alternativos no observados en la realidad.

El objetivo de este artículo es mostrar cómo debería la autoridad de la competencia orientar sus análisis económicos para obtener evidencia empírica contundente y rigurosa que permita determinar la existencia de la conducta colusiva, qué tan exitosa fue la coordinación entre las empresas del cártel y qué impacto generó tal práctica sobre el mercado. Para esto, se llevan a cabo dos ejercicios empíricos aplicados a uno de los casos más sonados de cartelización en los últimos años en Colombia: el "Caso Pañales". ${ }^{2}$ En el primer ejercicio, siguiendo la línea de análisis de la SIC, se hace un estudio muy detallado de las series de precios del mercado de pañales en colombia entre 2004 y 2016 para determinar si el comportamiento de los precios en el período de estudio responde efectivamente a acuerdos para la fijación de precios por parte de las empresas involucradas en el cartel o si más bien se debe a determinantes de mercado. Con este ejercicio, se corrobora lo que ya se ha documentado en la teoría y la evidencia internacional: los análisis de series de precios por sí solos pueden llevar a conclusiones equivocadas, ambigüas o contrarias a lo que se quiere demostrar. En efecto, se muestra que un análisis detallado de las series de precios arroja evidencia mixta que no permite concluir que existe un efecto en el mercado derivado de conductas restrictivas de la competencia sin agregar al análisis posibles presiones de oferta y demanda que pueden explicar los patrones observados dichas series. Adicionalmente, se encuentra que no existe evidencia empírica que muestre un cambio estructural en la variabilidad de los precios en ninguno de los segmentos analizados al comparar el período colusivo con el período postcolusión. Finalmente, dada la evidencia estadística se podría pensar que la cartelización de las empresas en el mercado de pañales desechables para bebé en Colombia, no parece haber tenido los efectos esperados sobre el mercado y, en particular, sobre los precios.

En el segundo ejercicio, se muestra cuál es el camino que conduce a un análisis de mercado que permita soportar sin ambigüedades una decisión de la autoridad. En este caso, se formula un modelo estructural de oferta y demanda para el mercado de pañales en Colombia, el cual se estima con base en los datos y, finalmente, se usa para simular escenarios alternativos al observado y calcular cuán cerca estuvieron los precios y márgenes sobre el costo marginal de las empresas del cartel con respecto a un referente monopólico, que es, de acuerdo con la teoría, el resultado ideal al que deberían llegar las empresas si lograran coordinarse perfectamente y maximizaran los beneficios conjuntos de la industria. Este ejercicio sugiere que las cifras del mercado están lejos de lo que debió observarse si el acuerdo colusivo se hubiera ejecutado bajo coordinación perfecta. Además, al comparar los resultados observados en el mercado con los

mente no lineales, los requerimientos en términos de datos son más altos (mayor desagregación y frecuencia), y los supuestos que se imponen a los datos son mucho mayores y más abstractos que aquellos que permiten construir relaciones lineales en los métodos en forma reducida.

${ }^{8}$ En las últimas décadas, el mercado de pañales desechables para bebé ha estado concentrada en tres empresas: Kimberly, Tecnosur (filial de Tecnoquímicas) y Familia. Estas tres empresas alcanzaron una participación de mercado conjunta de $93,6 \%$ en 2015 . El resto del mercado ha sido cubierto por empresas pequeñas, importaciones de pañales y marcas propias de supermercado. En 2012, la SIC inició una investigación por presuntos acuerdos entre Kimberly, Tecnoquímicas y Familia para la fijación de precios de sus productos en el período 2001-2012, que terminó en 2016 con una solución sancionatoria en la que se daba por probada la conducta restrictiva de la competencia y se imponían las multas más altas permitidas por la Ley: 206,8 miles de millones en total (Ver Resolución 86817 de 2016). 
que se obtendrían en casos de colusión perfecta entre las empresas investigadas, se muestra que la diferencia en las cifras indican que se estuvo lejos de alcanzar el resultado colusivo. La mejor explicación para esto es que los integrantes del acuerdo no estuvieran alineados con los objetivos del cartel, puesto que sus resultados difieren de los obtenidos en un escenario de coordinación perfecta.

Este artículo se compone de cuatro secciones. La primera ofrece una breve descripción de la política contra la colusión en Colombia y hace una descripción resumida de los casos más recientes de cartelización que ha investigado la SIC. La segunda sección hace una revisión de los avances que ha hecho la literatura económica en el análisis empírico de mercados en contextos colusivos, haciendo énfasis en el conjunto de métodos que permiten medir de manera rigurosa los efectos de un cartel en un mercado. En la tercera sección, tomando el caso de pañales presentamos una aplicación que tiene como objetivo mostrar qué debe contener un análisis económico de un mercado en un contexto colusivo que sirva como soporte de decisiones de política. Finalmente, se ofrecen conclusiones y recomendaciones.

\section{La política contra la colusión en Colombia}

La legislación colombiana para la protección de la competencia es una de las más antiguas de Latinoamérica. ${ }^{9}$ Sin embargo, la lucha activa y eficaz en este frente comenzó hasta después de la promulgación de la Ley 1340 de 2009 la cual definió a la SIC como la única autoridad nacional de competencia y le dio facultades para investigar y combatir de forma efectiva las prácticas restrictivas de la competencia. En efecto, entre 2010 y 2016 la SIC ha investigado y sancionado más casos de acuerdos entre empresas para fijar las condiciones del mercado (como precios) que nunca antes (ver tabla 1.

Una de las innovaciones más importantes que introdujo la Ley para la lucha contra la formación de carteles fue el Programa de Beneficios por Colaboración, que concede beneficios a aquellas personas (naturales o jurídicas) que denuncien la existencia de carteles y presenten pruebas contundentes que permitan identificar a los demás participantes y el avance rápido y efectivo en las investigaciones. Quien se acoja al programa, puede obtener una reducción parcial o total de la multa prevista por la Ley para estos casos. ${ }^{10}$ Este programa le ha permitido tener acceso a pruebas documentales contundentes que permiten emitir resoluciones sancionatorias sin que tales decisiones dependan de un análisis económico del mercado que permita analizar el impacto de las prácticas colusivas. Este énfasis en lo jurídico más que en lo económico es consistente con la filosofía de la Política de la Competencia que recomienda intervenir únicamente cuando existan pruebas contundentes (en inglés, hard evidence) sobre un acuerdo y no cuando se tengan sospechas o solamente con base en estudios económicos, por más que estos apunten a que los precios de mercado se encuentran muy por encima de un

\footnotetext{
${ }^{9}$ En 1959 se promulgó la Ley 155 que buscaba el control de prácticas comerciales restrictivas. Sin embargo, la falta de reglamentación la hizo casi inoperante.

${ }^{10}$ La Ley 1340 de 2009 fijó una multa máxima de 100 mil salarios mínimos mensuales vigentes para las empresas que incurran en una conducta restrictiva de la competencia, como un cartel. Según el Decreto 1523 de 2015, que reglamenta el Programa de Beneficios por Colaboración, los beneficios que se pueden otorgar a colaboradores dependen del momento en el que solicite la colaboración. El primer solicitante puede ser beneficiado con la reducción total de la multa a imponer. El segundo solicitante puede obtener entre un $30 \%$ y un $50 \%$ según la utilidad de la información aportada. El tercero y otros colaboradores subsiguientes podrán acceder al 25\% de reducción de la multa, dependiendo del valor de la información y las pruebas que aporten.
} 
Tabla 1: Colombia: algunos casos de colusión sancionados por la SIC, 2008-2016

\begin{tabular}{|c|c|c|c|c|}
\hline Año & Empresa & Tipo de caso & $\begin{array}{c}\text { Sanciones } \\
\text { (En millones) }\end{array}$ & $\begin{array}{l}\text { Resolución } \\
\text { No. }\end{array}$ \\
\hline 2008 & $\begin{array}{l}\text { Argos, Holcim, Cemex y } \\
\text { Andino }\end{array}$ & $\begin{array}{l}\text { Acuerdos para la fijación de precios, } \\
\text { la repartición de mercados y el } \\
\text { establecimiento de cuotas de producción }\end{array}$ & 2.769 & 51694 \\
\hline 2009 & $\begin{array}{c}\text { Compañía Nacional de Chocolates } \\
\text { Luker }\end{array}$ & Acuerdo para la fijación de precios & 1.491 & 4946 \\
\hline 2010 & $\begin{array}{l}\text { Ingenios: Incauca, Providencia, } \\
\text { Manuelita, Mayagüez, Pichichí, }\end{array}$ & Acuerdo para la fijación de precios & 8.240 & 42411 \\
\hline 2011 & $\begin{array}{l}\text { Risaralda, La Cabaña, Carmelita } \\
\text { RCN, Caracol, UCEP e IBOPE }\end{array}$ & $\begin{array}{c}\text { Acuerdo vertical para restringir } \\
\text { la competencia }\end{array}$ & 3.647 & 23890 \\
\hline 2011 & Consorcio Vial Colombiano & $\begin{array}{l}\text { Colusión para acordar términos } \\
\text { en licitación y definir un ganador }\end{array}$ & 2.142 & 64400 \\
\hline 2011 & $\begin{array}{c}\text { Fendipetróleo y Estaciones de } \\
\text { servicio Boyacá }\end{array}$ & $\begin{array}{c}\text { Paralelismo de precios y acuerdos } \\
\text { para fijación de precios }\end{array}$ & 8.570 & 71794 \\
\hline 2013 & $\begin{array}{l}\text { Unión Temporal Cárceles } 2008 \text { y } \\
\text { Unión Temporal Seguridad Carcelaria }\end{array}$ & $\begin{array}{l}\text { Colusión para acordar términos } \\
\text { en licitación y definir un ganador }\end{array}$ & 3.967 & 8917 \\
\hline 2013 & Grupo Nule & $\begin{array}{l}\text { Colusión para acordar términos } \\
\text { en licitación y definir un ganador }\end{array}$ & 15.687 & 54693 \\
\hline 2013 & Grupo Nule & $\begin{array}{l}\text { Colusión para acordar términos } \\
\text { en licitación y definir un ganador }\end{array}$ & 13.072 & 54695 \\
\hline 2014 & $\begin{array}{c}\text { Incoequipos, Gisaico, ESTYMA, } \\
\text { Pavigas }\end{array}$ & $\begin{array}{l}\text { Colusión para acordar términos } \\
\text { en licitación y definir un ganador }\end{array}$ & 5.927 & 83037 \\
\hline 2015 & $\begin{array}{l}\text { ASOCAÑA, CIAMSA e Ingenios: } \\
\text { Riopaila Castilla, Cauca, Manuelita, } \\
\text { Providencia, La Cabaña, Pichichí, } \\
\text { Risaralda, San Carlos, Carmelita, } \\
\text { Central Tumaco, María Luisa }\end{array}$ & $\begin{array}{l}\text { Acuerdos para la asignación de } \\
\text { cuotas de producción o de } \\
\text { suministro e impedir acceso } \\
\text { de terceros a mercados }\end{array}$ & 216.786 & 103652 \\
\hline 2016 & $\begin{array}{c}\text { Kimberly Colpapel, Scribe Colombia y } \\
\text { Carvajal Educación }\end{array}$ & $\begin{array}{c}\text { Acuerdo para la fijación de precios } \\
\text { "Caso Cuadernos" }\end{array}$ & 56.188 & 54403 \\
\hline 2016 & $\begin{array}{c}\text { Kimberly Colpapel, Tecnoquímicas, } \\
\text { Familia }\end{array}$ & $\begin{array}{l}\text { Acuerdo para la fijación de precios } \\
\text { "Caso Pañales" }\end{array}$ & 206.837 & 86817 \\
\hline 2016 & $\begin{array}{l}\text { Kimberly, Familia, Papeles Nacionales, } \\
\text { C. Y P. Del R. }\end{array}$ & $\begin{array}{l}\text { Acuerdo para la fijación de precios } \\
\text { "Caso Papeles Suaves" }\end{array}$ & 183.395 & 31739 \\
\hline
\end{tabular}

Fuente: Superintendencia de Industria y Comercio. 
referente competitivo.

Sin embargo, los análisis económicos rigurosos y a profundidad del mercado siguen siendo necesarios para determinar la magnitud del daño, más que la existencia o no del acuerdo. En especial, para el caso colombiano tales estudios son fundamentales para determinar el monto de la multa, tal como lo dispone el Ley 1340 de 2009. ${ }^{11}$

\section{Análisis de colusión, estructura de mercado e impactos: lecciones de la literatura empírica}

De acuerdo con la definición de colusión, la cual se refiere a un resultado de mercado en el que los precios se encuentran por encima del que sería el precio en un mercado competitivo, la literatura empírica inicialmente se centró en realizar estudios basados en el análisis estadístico de los precios, dada la dificultad de observar o estimar el precio competitivo. En consecuencia, características fáciles de medir de un acuerdo o conspiración de tipo colusivo fue en principio el enfoque predominante de los esfuerzos académicos y, por ende, de las autoridades regulatorias para la identificación del mismo. Este enfoque se conoce como behaviorial approach y se centra en medir el impacto de los esfuerzos de coordinación de las empresas sobre los resultados del mercado (Harington, 2008). El escrutinio de los comportamientos o conductas de coordinación de las empresas se centra en el uso de métodos estadísticos útiles para indicar si mercados específicos han sido afectados por comportamientos colusivos entre las empresas, los cuales se reflejan de acuerdo a la literatura teórica y empírica principalmente en tres situaciones: i) cambios en la varianza de los precios durante los períodos de colusión y paralelismo en los niveles de precios entre empresas, ii) cambios en el comportamiento de los precios en relación con cambios en la demanda y oferta del mercado y iii) cambio estructural en la volatilidad de los precios.

En primer lugar, teóricamente, los acuerdos de precios entre empresas propios de un comportamiento colusivo se reflejan en una menor variabilidad de los precios, una mayor presencia de ciclos en los precios y también en una menor variabilidad de las cuotas de mercado (market shares). Estos resultados fueron derivados por Maskin y Tirole (1988) en un modelo de duopolio homogéneo en un contexto dinámico, por LaCasse (1995) en un modelo con colusión endógena con biddings, y luego constatado en un juego infinito a la Bertrand en el cual las firmas eligen precios pero los costos son variables independientes e idénticamente distribuidas sobre el tiempo y a través de las empresas, y se constituye como información privada de cada empresa (ver Athey et al. (2004), Harrington and Chen (2006)). Empíricamente, la ausencia de variabilidad en los niveles de precios durante los períodos de colusión ha sido mostrado por Levenstein and Suslow (2006), Bolotova et al. (2008), Genesove and Mullin (2001), Feinstein et al. (1985), entre otros.

En suma, el comportamiento estratégico de los jugadores en un mercado teóricamente predice una disminución en la varianza de los precios durante el periodo de acuerdo de precios (Carlson and McAfee, 1983 y Carlton, 1986); así como también, movimientos abruptos de la media y la varianza de los precios alrededor del periodo de finalización del cartel (ver Har-

\footnotetext{
${ }^{11}$ El artículo 25 de la Ley 1340 de 2009 que trata sobre el monto de las multas a personas jurídicas, dispone lo siguiente: "[...] Para efectos de graduar la multa, se tendrán en cuenta los siguientes criterios: 1) El impacto que la conducta tenga sobre el mercado; 2) La dimensión del mercado afectado; 3) El beneficio obtenido por el infractor de la conducta; ...6) la cuota de mercado de la empresa infractora..."
} 
rington, 2005, Abrantes-Metz et al., 2006). Sin embargo, tradicionalmente, las autoridades regulatorias se enfocan en un análisis estadístico de los precios centrado en el comportamiento medio de los mismos, ignorando los momentos de orden superior de la distribución empírica de los datos históricos. Adicionalmente, en la literatura es común identificar patrones de comportamiento dinámico tanto de los precios como de las participaciones de mercado, basándose en la comparación de periodos de competencia versus periodos de comportamiento anticompetítivo. Este tipo de análisis se conoce como escrutinio de mercado y es un método diseñado para captar, señalar o identificar la transición de competencia a colusión al encontrar diferencias radicales en el comportamiento de las empresas entre estas dos fases, las cuales naturalmente deben verse reflejadas en cambio abruptos en el comportamiento de los precios (Harrington, 2006). Sin embargo, la literatura empírica ha mostrado que la presencia de tendencias temporales en los precios pueden sesgar la media y la varianza de los datos, cuando se compara un periodo de cartelización con uno de competencia; esto dadas las diferencias en la duración de estas dos fases. En consecuencia, para identificar las diferencias en el comportamiento de precios es indispensable comparar la distribución completa de los cambios en los precios teniendo como referencia un periodo competitivo, el cual puede ser pre-cartel y/o pos-cartel (ver Connor (2005), Blanckenburg (2013)).

Adicionalmente, se ha demostrado que los carteles cambian sus precios con menor frecuencia de lo que lo harían bajo un comportamiento competitivo. Esto debido a las dificultades que pueden enfrentar en sus procesos de negociación (los cuales incluyen tiempo de negociación, de coordinación y adaptación de precios) que pueden llevar a procesos de decisión lentos y a la falta de celeridad de reacción del cartel frente a choques de demanda o de oferta en el mercado (ver Carlson y Mcfee (1983), Carlton(1986)). En consecuencia, en la literatura se han identificado un conjunto de características que pueden dar indicios sobre la posible conducta colusiva de los competidores en un mercado. Dichas características surgen de la comparación del cambio en los precios entre un periodo de colusión contra un periodo de competencia de un conjunto de diversos casos estudiados en el mundo, y se pueden resumir en: (1) tendencia de cambios escalonados en los precios, (2) variación en la dispersión (varianza) de los cambios en los precios, (3) incremento en la curtosis de los cambios en los precios, y (4) incremento en la asimetría de los cambios en los precios.

También se ha mostrado que la distribución de los cambios en los precios durante un periodo de cartelización tiende a tener un pico alrededor de cero, lo cual se traduce en un mayor exceso de curtosis; esto derivado de la necesidad de periodos de negociación de los precios que retrasan los cambios en éstos (Coonor, 2004). Adicionalmente, la evidencia empírica ha mostrado que los carteles están mucho menos inclinados hacia la reducción de precios que las firmas competitivas, aun cuando el cartel pudo haberse establecido en un periodo de caída en los precios. En consecuencia, cambios positivos de precios deberían ocurrir más frecuentemente que cambios negativos durante el periodo de cartelización, es decir, se esperaría un coeficiente de asimetría positivo. Finalmente, Green and Porter (1984) mostraron que los cambios en los precios están positivamente correlacionados con choques de demanda positivos, mientras que los ajustes a choques negativos se dan con mayor dificultad, lo que implica otra causa de asimetría positiva en los precios.

En segundo lugar, teóricamente se ha determinado que durante el periodo de colusión la relación entre los precios y la oferta de mercado es negativa, por lo que es posible que los precios sean insensibles a cambios estacionales en la demanda (Bejger, 2011 y 2010, Rotemberg and Saloner, 1986). Sin embargo, Haltinwanger and Harrington (1991) relajando el supuesto 
de procesos independientes e idénticamente distribuidos, analizan los componentes determinísticos cíclicos de la demanda y encuentran un comportamiento procíclico de los precios. En consecuencia, se debe verificar: (1) si existe una relación causal entre los precios y oferta; y (2) si los precios son procíclicos o insensibles a los cambios determinísticos cíclicos en la demanda.

En tercer lugar, el análisis de cambios estructurales en el nivel y en la volatilidad de los precios es fundamental para develar eventos que hayan conducido a un cambio claramente identificable en la manera como funciona un mercado. El análisis de cambios estructurales permite dar luces sobre los procesos de formación o terminación de carteles y los cambios propios en el comportamiento de las empresas en dichos procesos. Sin embargo, es muy importante tener en cuenta que eventos tales como fusiones, salidas o entradas de empresas, avances tecnológicos de alguna relevancia, etc pueden generar también cambios estructurales en el mercado. En consecuencia, Frederiszick y Maier-Rigaud (2008) afirman que para identificar estos eventos críticos deben responderse dos preguntas basadas en la recolección de la información de la industria analizada: a) ¿es posible identificar choques exógenos que generen reacciones diferentes en un ambiente cartelizado versus en un ambiente competitivo?; b) ¿es posible observar cambios estructurales que no puedan ser explicados si trascurriesen en un ambiente competitivo?. Por ende, para que el análisis estadístico sea confiable se debe controlar por factores de demanda y oferta que puedan haber cambiado sobre el tiempo, de tal forma que la modelación permita una comparación válida de precios en un contexto de cambio en las condiciones del mercado. Como pruebas de robustez de estos análisis se pueden considerar comparaciones de precios entre mercados colusivos y no colusivos durante el mismo lapso de tiempo. Esto se puede realizar analizando las diferencias en los precios de la empresas bajo investigación con respecto a una relativamente similar pero que no esté sometida a sospecha, la cual puede ser tomada como referente o benchmark. Así mismo, se pueden analizar diferentes mercados geográficos, que puedan ser comparables con el mercado sujeto análisis.

Finalmente, es importante enfatizar que los análisis antes mencionados presentan una limitación fundamental en cuanto a que muchas de las características bajo estudio pueden aun estar presentes en situaciones no colusivas. Es así como, el uso de análisis descriptivo en forma reducida sirven para señalar situaciones que podrían ser consistentes con una colusión, pero que no se configuran como una prueba irrefutable de la misma, por lo que debe considerarse como solo una parte de la evidencia final que sirve para determinar si existe una conducta colusiva. En consecuencia, a menudo las autoridades encargadas de proteger la competencia caen en el error de juzgar el nivel de competencia en una industria basadas en observaciones simples de las variables principales del mercado, especialmente precios y participaciones de mercado. En muchas ocasiones, el hecho de que las empresas tengan cierto poder de mercado que se traduce en márgenes de rentabilidad positivos, son catalogados como evidencia de conductas restrictivas de la competencia, puesto que se tiene en mente el resultado extremo de la teoría económica según el cual una industria competitiva es aquella en la que las empresas fijan precios cercanos al costo marginal y, por lo tanto, su rentabilidad tiene que tender a cero.

Sin embargo, la academia ha insistido en que los resultados económicos de una industria no se pueden tomar como evidencia de prácticas anticompetitivas o abusivas, ni los márgenes de rentabilidad positivos pueden interpretarse como signo de alerta o prueba de que una industria no es competitiva, como tampoco resultados de estabilidad de precios sugeridos por un análisis descriptivos del mercado, ni mucho menos tomando como referencia el modelo teórico que arroja el resultado competitivo ideal. Estos análisis enfocados a responder preguntas de si 
los precios en una industria pueden ser más bajos y la competencia más intensa (lo cual se conoce como escenarios 'contrafactuales') requieren de una modelación estructural (que combina teoría y evidencia empírica) que explique el funcionamiento de la industria teniendo en cuenta todos los agentes que en ella intervienen (oferta y demanda) y sus reacciones ante cambios en el precio y otras variables que influyen en las decisiones de dichos agentes.

Un análisis de este tipo implica el desarrollo un modelo estructural de demanda, el cual sirve de base para la estimación de la demanda usando métodos econométricos tradicionalmente paramétricos. Una estimación en forma estructural permite recuperar los márgenes brutos totales por unidad por marca (definidos como precio menos costo marginal) y, por ende, la simulación de escenarios alternativos con base en diferentes estructuras de oferta. Esta metodología está basada de manera importante en las contribuciones académicas de Berry (1994), Berry, Levinsohn y Pakes (1995) y Nevo (2000a,b; 2001).

\section{Análisis de colusión en la práctica: una aplicación al caso colombiano}

En esta sección se presenta un análisis empírico del mercado de pañales en el período 20042016, desde dos enfoques: por un lado, análisis forma reducida con base en modelos de series de tiempo. Por otro lado, un enfoque estructural que permite usar los datos para estimar un modelo económico del mercado y simular escenarios alternativos al observado y hacer análisis de estática comparativa.

\subsection{La industria de pañales para bebé y la investigación de la SIC}

La industria de pañales desechables para bebé se ha caracterizado por su alta concentración en pocas empresas, que han dominado históricamente el mercado; la casi nula entrada de nuevos competidores, además de la baja participación de marcas importadas; la entrada y salida constante de marcas y variedades de pañales, aunque ha sido constante la disponibilidad de una gama relativamente amplia de alternativas diferenciadas en términos de marca, con un promedio en la última década de 7 marcas producidas por empresas distintas, y en términos de calidad, con cinco segmentos que van desde el pañal básico hasta el pañal premium; y una competencia intensa en estrategias de mercado distintas al precio, tales como publicidad. Adicionalmente, hay una pequeña pero consistente participación de supermercados con sus propias marcas, que son generalmente más baratas que las marcas de fabricantes independientes.

Hacia finales de la década del noventa, el mercado de pañales para bebé en Colombia estaba dominado por Kimberly Colpapel, con un $80 \%$ de participación de mercado. Su competencia más importante venía esencialmente de Tecnosur (hoy filial de Tecnoquímicas), que participaba en el mercado con un 18\%, además de Familia y de algunas marcas importadas. En los primeros años de la década de 2000, el mercado pasó a repartirse entre Kimberly, Tecnosur y Familia, que lograron aumentar su participación a costa de la parte de Kimberly. ${ }^{12}$

\footnotetext{
${ }^{12}$ A finales de la década del noventa, Tecnoquímicas vendió a Kimberly el $50 \%$ de su empresa productora de pañales, Tecnosur. La propiedad compartida de Tecnosur se mantuvo hasta principios de 2014, cuando Tecnoquímicas llegó a un acuerdo de recompra con Kimberly y volvió a ser el dueño único de Tecnosur. Según las declaraciones dadas a la SIC con motivo de la investigación por el "Caso pañales", a pesar de la propiedad compartida, Tecnosur mantuvo la discreción total sobre sus políticas de precios y mercadeo de sus productos (SIC, 2016, p. 17). Además, la pérdida de participación de mercado que experimentó Kimberly frente a
} 
La figura 1 muestra las series de participaciones de mercado de las principales productoras de pañales desechables para bebé entre 2004 y 2015. Como lo muestra la figura, Tecnosur se posicionó como líder del mercado con una participación promedio del $42 \%$ en el volumen de ventas totales, mientras que Familia y Kimberly la siguieron con participaciones promedio del $25,6 \%$ y $23,2 \%$, respectivamente. Entre 2006 y 2014, Familia logró ganarle terreno a Kimberly y posicionarse como la segunda empresa en ventas de pañales después de Tecnosur. En el año 2015, estas tres empresas concentraban conjuntamente el 93,6\% del volumen de ventas de pañales para bebé. El resto del mercado ha sido cubierto por empresas pequeñas (Drypers ha sido la cuarta empresa más importante del mercado con una participación promedio de $5,8 \%$ ), importaciones de pañales y marcas propias de supermercado.

En 2012, la SIC recibió una denuncia sobre presuntos acuerdos entre Kimberly, Tecnoquímicas y Familia para la fijación de precios de sus productos. En febrero de 2014 un memorando radicado por el Superintendente Delegado para la Protección de la Competencia ordenó iniciar una investigación preliminar para establecer si existía evidencia de prácticas comerciales restrictivas de libre competencia ejecutadas por las empresas Kimberly, Tecnoquímicas y Familia en el mercado de distribución y comercialización de pañales desechables para bebé en Colombia. En agosto del mismo año la delegatura ordenó abrir una investigación y formular pliego de cargos contra Kimberly, Familia, Tecnoquímicas, Tecnosur y Drypers para determinar si incurrieron en la conducta de realizar acuerdos contrarios a la libre competencia en los cuales se mantengan o determinen precios. Las imputaciones se sustentaron en declaraciones, correos electrónicos y documentos hallados durante visitas administrativas, que darían cuenta de que Kimberly, Tecnoquímicas, Familia, Tecnosur y Drypers habrían fijado precios de pañales desechables para bebé en Colombia (SIC, 2016, p. 15). Según esta evidencia, la determinación coordinada de precios se dio tanto de manera directa, mediante la determinación de precios de salida para los productos y los porcentajes de incremento correspondientes, como de forma indirecta a través aspectos relacionados con la concesión de descuentos e incentivos. La investigación terminó en 2016 con una resolución sancionatoria en la que se concluyó que Kimberly, Familia y Tecnoquímicas incurrieron en "actos ilegales de cartelización empresarial para fijar artificialmente el precio de los pañales desechables para bebé en el mercado colombiano" entre 2001 y 2012, y se impusieron las multas más altas permitidas por la Ley que entre las tres sancionadas suman 206,8 miles de millones. ${ }^{13}$

Si bien la SIC logró recolectar pruebas que apuntan a que las empresas hicieron esfuerzos para coordinar sus precios, lo que según la Ley y la lógica de la Política de la Competencia sancionable, no existe evidencia ni referencia de la SIC a pruebas sobre acuerdos adicionales para acordar repartición de mercado o acuerdo sobre participación, los cuales son elementos esenciales para que conjuntamente con los precios se de una cartelización efectiva. De otra parte, en el plano económico, su análisis es muy limitado y sus conclusiones no están adecuadamente soportadas por lo que muestran los modelos utilizados y los datos. En efecto, en el "Informe Motivado del Caso pañales" la SIC afirma que "... las variabilidades relativas del componente cíclico de las series de precios promedio, se acotaron en torno de la tendencia,

Tecnosur en el período de propiedad compartida, no soporta la hipótesis de una coordinación perfecta entre empresas que buscaría suavizar la competencia entre marcas. Por esta razón, en éste ejercicio se considerará a Tecnosur como una empresa independiente de Kimberly.

${ }^{13}$ Ver Resolución 86817 de 2016. Aunque Drypers figura entre las empresas que hicieron parte del cartel hasta 2006, no hizo parte de la sanción debido a que, según la SIC, hubo vencimiento de términos fijados por la Ley para cualquier actuación. 
Figura 1: Evolución de las participaciones de mercado por productor, 2004-2015

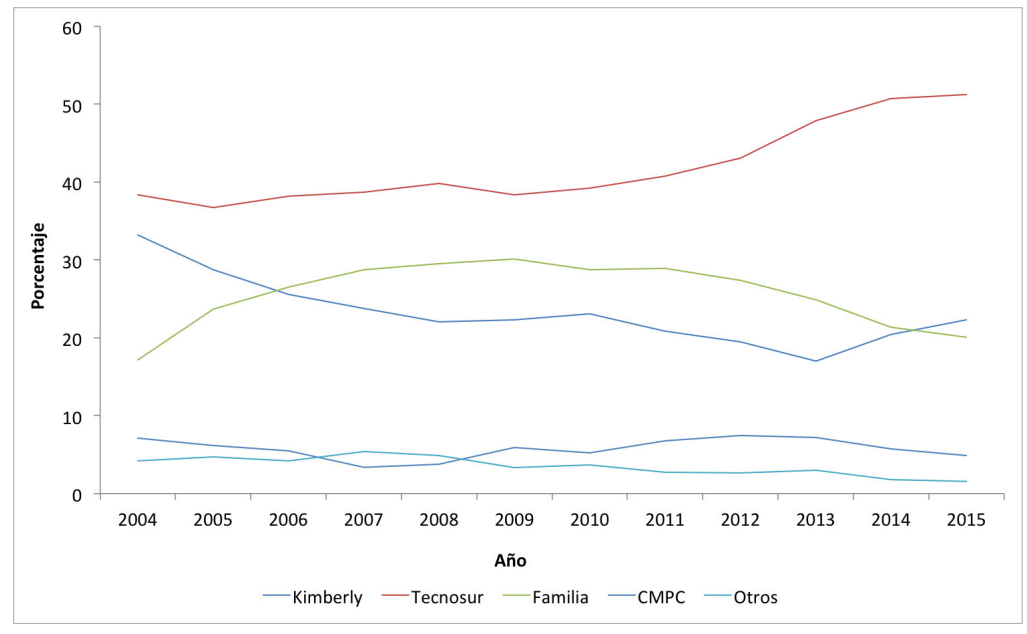

Fuente: Nielsen.

y las distribuciones de probabilidad KERNEL resultaron bastante coincidentes. Esto podría indicar que, las probabilidades de las variaciones relativas del componente cíclico son iguales o muy similares, esto es un indicio concreto de la existencia de coordinación en las decisiones de precios." (SIC, 2016, p. 222). Sin embargo, y como ya se ha mencionado antes, observar que la distribución de variaciones en los precios sea similar entre empresas no necesariamente implica coordinación en la fijación de precios.

Adicionalmente, la SIC señala que cambios en la participación en el mercado no son indicativos de la ausencia de un acuerdo. Pero no hace referencia a la dificultad que esto supone para la estabilidad de cualquier acuerdo colusivo. Otro comportamiento que no considera importante en el análisis es la competencia por medio de calidad. Al respecto, reconoce que el "lanzamiento de nuevos productos y mejora en los existentes, es una constante que se ha presentado en todos los agentes del mercado de pañales desechables para bebé" (SIC, 2016, p. 237). A pesar de este reconocimiento, la SIC no tiene en cuenta este hecho como evidencia de que las empresas compiten intensamente en otras variables estratégicas diferentes al precio, lo que constituye un indicio importante de rivalidad entre empresas. En un ambiente de competencia suave y alta concentración, se esperaría que factores como la publicidad y la calidad se mantuvieran constantes o se coordinaran también.

Estos argumentos motivan las siguientes preguntas: ¿Qué sugiere la similitud en el comportamiento de los precios y su aumento persistente en el mercado de pañales? ¿Cómo determinar qué tan coordinadas estaban las empresas y cuán rentable fue el cartel? El objetivo de esta sección es analizar los datos del mercado de pañales a profundidad para responder a estas preguntas.

\subsection{Datos}

Los datos usados para este ejercicio empírico fueron recolectados por Nielsen entre enero de 2004 y marzo de 2016. La base original presenta datos sobre ventas en volumen y valor total 
de dichas ventas a nivel de marca (alrededor de 22 en total), segmento (o tier en inglés, 5 en total) y etapa (edad del bebé), agregadas por región geográfica ${ }^{14}$ y por bimestre, entre 2004 y 2007, y por mes a partir de 2008. Dado el nivel de agregación de los datos en los años iniciales, se agregó el resto de períodos al nivel bimensual para explotar la información en todo el período. La base de datos también contiene información sobre el fabricante de la marca (al menos 10 incluyendo pequeños fabricantes y fabricantes de marcas propias de supermercados).

Estos datos presentan una gran cantidad de ceros y datos faltantes que dificultan su explotación al nivel de desagregación original. Debido a esto, en los análisis que se presentan a continuación se agregaron los datos para eliminar las dificultades asociadas a datos faltantes dependiendo de las necesidades del modelo.

\subsection{Análisis de la Dinámica de Precios en la Industria de Pañales Desechables para Bebé, 2004-2016}

\subsubsection{Análisis de la Distribución de los Cambios en los Precios}

Con el fin de analizar los posibles cambios en la distribución de las variaciones en los precios, el periodo de tiempo entre enero de 2004 hasta marzo de 2016 se divide, de acuerdo con el informe motivado presentado por la SIC, en dos subperiodos: periodo de cartel (20042011) y periodo pos-cartel o competencia (2012-2016). Siguiendo a Blanckerburg, et. al 2011, se usan precios nominales en razón a que el comportamiento de la inflación en los dos subperiodos no es homogénea, en el sentido de que las dos fases no comparten de la misma manera los incrementos y caídas en la tasa de inflación, por lo que esto podría sesgar los resultados, principalmente el coeficiente de asimetría de las distribuciones en los dos periodos bajo análisis.

En la Figura 2 se presentan el comportamiento de los precios, entre enero de 2004 y marzo de 2016, de todas las empresas involucradas en las acusaciones: Drypers, Kimberly, Familia y Tecnosur. Las gráficas se hacen teniendo en cuenta los dos segmentos más representativos en términos de ventas en el mercado de pañales de bebé Tiers 2 y 4 , de acuerdo con el Informe Motivado de la SIC. Las series de precios se agregan al nivel nacional e incluyen todos los canales comerciales. Con fines comparativos se incluye la serie de precios de los demás competidores en el mercado (identificada como OTROS) que no son objeto de investigación, la cual corresponde a un promedio ponderado teniendo en cuenta la respectiva participación de mercado. Las líneas punteadas horizontales corresponden a las fechas en las cuales, de acuerdo con el Informe Motivado, las empresas bajo investigación acordaron una política de precios y descuentos o las dos, las cuales fueron identificadas como: diciembre 2005, junio de 2006, diciembre de 2007, marzo de 2009, diciembre 2010 y marzo de 2011.

Con el fin de analizar qué tan frecuentemente hubo cambios en los precios en el mercado de pañales en la Figura 2 se observa, en primer lugar, que no existen variaciones escalonadas en ninguna de las series de precios, las cuales representan un comportamiento propio de los precios en un mercado cartelizado. En segundo lugar, tampoco existe un tendencia creciente o decreciente clara en los precios de ninguna de las empresas analizadas en el segmento T2; mientras que, con excepción de los precios de OTROS y Drypers, se observa que los precios del segmento T4 presentan un tendencia decreciente, la cual se revierte a mediados de 2014.

\footnotetext{
${ }^{14}$ Las regiones incluidas son: Antioquia, Atlántico, Centro, Cundinamarca, Oriente y Pacífico.
} 
Figura 2: Evolución del comportamiento histórico de los precios, 2004-2016
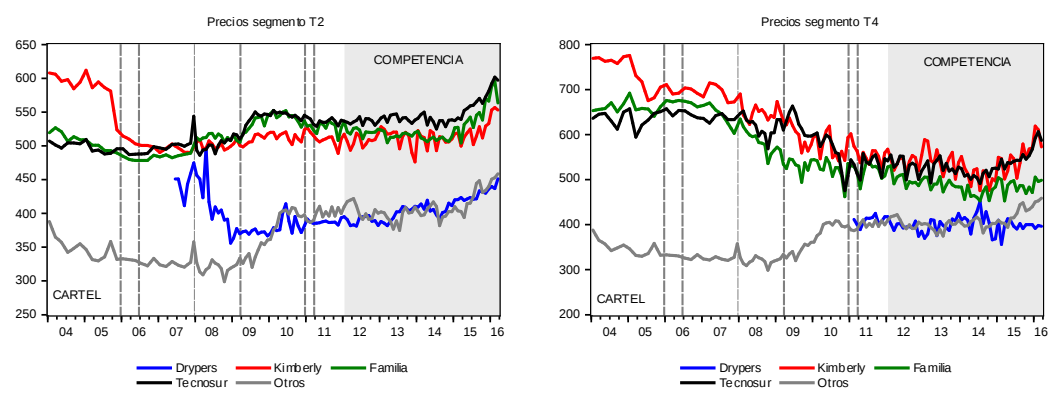

Fuente: Nielsen y OMD. Cálculos del autor.

Esta observación es confirmada por el análisis de los precios teniendo en cuenta su posible estacionalidad, como se muestra en la Figura 3. Este análisis, sin embargo, revela el cambio estructural ocurrido en 2009 en el comportamiento del nivel de precios de OTROS competidores, en donde los precios pasan de tener una tendencia decreciente a una tendencia creciente al presentar un fuerte cambio en su nivel al pasar de $\$ 320$ a $\$ 420$ por unidad en el segmento T4. Finalmente, es de notar que en el segmento T2, los precios de Tecnosur siguen un comportamiento muy similar al de OTROS competidores, y que no existe una evidencia clara de coordinación que haya afectado de manera exclusiva a los precios en las fechas señaladas por la SIC, ya que por ejemplo en diciembre de 2007 todos los precios presentaron un incremento.

En la Tabla 2 se presenta un resumen de estadística descriptiva de los cambios en los precios para los dos periodos bajo análisis. De la comparación entre el periodo de cartel con respecto al periodo de competencia se observan cambios en la media, la varianza, y los niveles mínimo y máximo de las tasas de crecimiento de los precios de todas las empresas. En particular, se observa una disminución en la desviación estándar del segmento T4, el cual se corresponde con la reducción que se presenta en OTRAS empresas. Para el segmento T2, se observa un aumento en la desviación estándar en el caso de Kimberly y Familia; mientras que se observa un disminución en Tecnosur de 0.6 unidades la cual es equivalente a la reducción de las OTRAS empresas en el mercado que funcionan bajo una estructura competitiva. Teóricamente se esperaría un aumento importante en la variabilidad de los precios en el periodo de pos-acuerdo exclusivo de las empresas involucradas en los acuerdos, dado el aumento en la competencia; sin embargo, no se observa dicho comportamiento en este mercado.

Dado que las estadísticas descriptivas solo permiten un análisis estático con respecto al nivel medio de las series, en la Figura 4 se muestran los cambios en los precios de cada una de las empresas en el periodo 2004-2016. Las gráficas muestran que hubo un aumento en la volatilidad de los precios a partir del 2008, el cual coincide con la crisis financiera más reciente. Sin embargo, este aumento en la variabilidad de precios es común a todas las empresas en los dos segmentos y se mantienen hasta el final del periodo. Este resultado, sumado a los anteriores, sugiere que la variabilidad en los cambio de los precios podría estar afectada por choques aleatorios exógenos que afectaron el mercado en su conjunto. Sin embargo, el análisis 
Figura 3: Evolución del comportamiento estacional de los precios
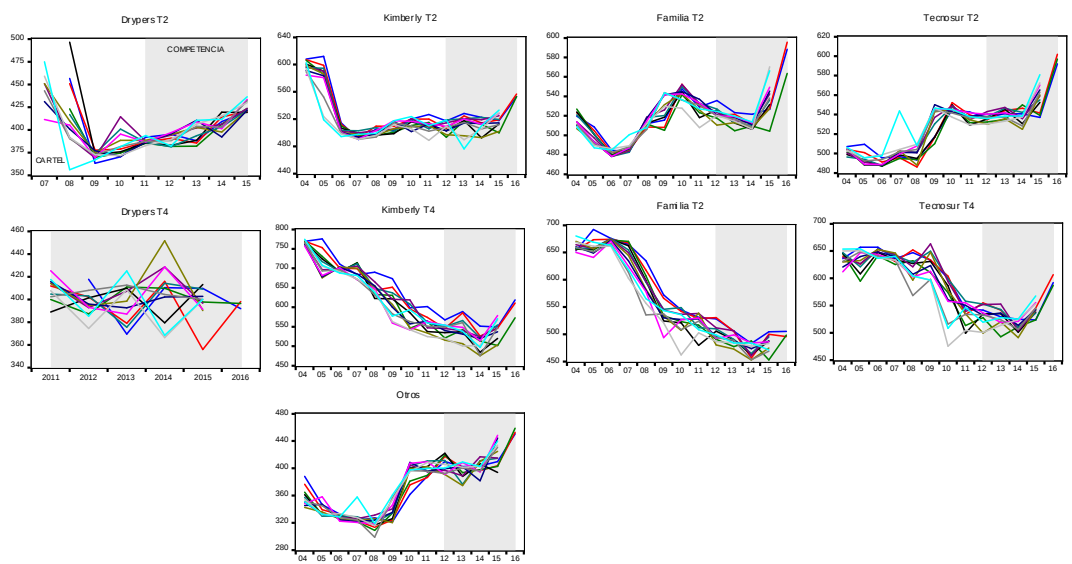

Fuente: Nielsen y OMD. Cálculos del autor.

Tabla 2: Estadística descriptiva para los cambios en los precios

\begin{tabular}{|c|c|c|c|c|c|c|c|c|c|}
\hline & \multicolumn{4}{|c|}{$\mathrm{T} 2$} & \multicolumn{4}{|c|}{$\mathrm{T} 4$} & \multirow[b]{2}{*}{ Otros } \\
\hline & Drypers & Kimberly & Familia & Tecnosur & Drypers & Kimberly & Familia & Tecnosur & \\
\hline \multicolumn{10}{|l|}{ Cartel } \\
\hline Media & $-0,15$ & 0,05 & 0,17 & 0,15 & 0,04 & 0,20 & 0,04 & 0,20 & 0,43 \\
\hline Mediana & 0,12 & 0,11 & 0,20 & $-0,05$ & 0,00 & $-0,49$ & 0,35 & 0,81 & 0,75 \\
\hline Max & 1,73 & 4,39 & 3,77 & 7,87 & 1,17 & 1,06 & 7,69 & 8,62 & 9,18 \\
\hline Min & $-1,60$ & $-2,67$ & $-4,37$ & $-9,26$ & $-1,31$ & $-1,07$ & $-9,46$ & $-9,51$ & $-8,55$ \\
\hline Std. Dev. & 4,64 & 1,45 & 1,51 & 1,98 & 5,32 & 5,52 & 3,86 & 3,54 & 3,11 \\
\hline Asimetría & 0,21 & 0,53 & $-0,16$ & $-0,87$ & $-0,07$ & $-0,06$ & $-0,35$ & $-0,57$ & $-0,25$ \\
\hline Curtosis & 7,39 & 3,70 & 3,50 & 1,45 & 3,16 & 1,98 & 2,84 & 3,76 & 3,96 \\
\hline Jarque-Bera & & & & & & & & & \\
\hline $\mathrm{p}$-valor & 0,00 & 0,163 & 0,681 & 0,00 & 0,954 & 0,326 & 0,577 & 0,135 & 0,267 \\
\hline \multicolumn{10}{|l|}{ Competencia } \\
\hline Media & 0,28 & 0,20 & 0,15 & 0,21 & 0,18 & $-0,29$ & $-0,21$ & $-0,11$ & 0,30 \\
\hline Mediana & 0,28 & 0,23 & 0,14 & 0,43 & 0,86 & $-0,22$ & $-0,24$ & 0,01 & 0,47 \\
\hline $\operatorname{Max}$ & 3,35 & 9,72 & 5,94 & 2,47 & 4,08 & 9,39 & 1,60 & 1,18 & 7,32 \\
\hline Min & $-3,82$ & $-5,07$ & $-5,39$ & $-3,51$ & $-5,38$ & $-1,14$ & $-9,17$ & $-7,85$ & $-6,94$ \\
\hline Std. Dev. & 1,57 & 2,87 & 2,06 & 1,32 & 2,97 & 3,11 & 3,20 & 3,03 & 2,54 \\
\hline Asimetría & 0,02 & 0,48 & 0,15 & $-0,53$ & $-0,60$ & $-0,09$ & 1,23 & 0,65 & $-0,03$ \\
\hline Curtosis & 2,90 & 4,17 & 4,54 & 3,02 & 2,24 & 5,09 & 9,89 & 5,66 & 3,77 \\
\hline Jarque-Bera & & & & & & & & & \\
\hline $\mathrm{p}$-valor & 0,989 & 0,088 & 0,072 & 0,303 & 0,658 & 0,00 & 0,00 & 0,00 & 0,529 \\
\hline
\end{tabular}

Fuente: Nielsen y OMD. Cálculos del autor. 
incondicional del comportamiento dinámico de las series de precios no se constituye como una prueba irrefutable de la existencia o no de un acuerdo de precios, ya que este tipo de análisis no revela los posibles determinantes asociados a una menor variabilidad en el cambio de los precios de las empresas involucradas en un comportamiento anticompetitivo. Tampoco se puede concluir que el cambio en la variabilidad observada se debe al cambio del periodo del cartel al del periodo competitivo.

Dado que el análisis del comportamiento medio y de la volatilidad en los precios no es concluyente con respecto al efecto de la conducta anticompetitiva investigada sobre los precios; se procedió a realizar una estimación no paramétrica de las distribuciones de densidad empíricas de los cambios en los precios para cada uno de los dos subperíodos. La Figura 5 muestra la densidad empírica para las empresas agrupadas en OTROS en el mercado de pañales. La densidad fue estimada usando un Kernel Gausiano con un parámetro de suavizamiento determinado por la rule-of-thumb dado por:

$$
h=(0.9) \min (\sigma, I Q R) / 1.34 N^{-1 / 5}
$$

donde $\sigma$ es la desviación estándar, $I Q R$ es el rango intercuartil y $N$ es el número de observaciones en la muestra. De acuerdo con la investigación realizada por la SIC en el mercado de pañales desechables para bebé, las empresas en la categoría OTROS presentaron un comportamiento competitivo durante todo el periodo de análisis, por lo que se pueden tomar como referencia de cómo tendría que haberse comportado el precio y sus cambios entre 2004 y 2016.

La comparación de las dos distribuciones, a partir de la Figura 5, muestran una diferencia importante en términos de la asimetría de los cambio en los precios. En efecto, el coeficiente de asimetría entre 2004 y 2011 fue de -0,24, mientras que entre 2012 y 2016 fue de -0,03, lo cual evidencia que tasas de crecimiento negativas de los precios fueron observadas en ambos periodos siendo más asimétricos en el periodo de cartelización. Adicionalmente, se observa que la distribución empírica de los cambios en los precios fueron más leptocurticos entre 2004 y 2011 que entre 2012 y 2016.

En las Figuras 6 y 7 se muestran las densidades empíricas de los cambios en los precios para las empresas objeto de investigación en el mercado de pañales, diferenciando los segmentos T2 y T4 y los dos sub-periodos. En primer lugar, se observa exceso de curtosis alrededor de cero en el periodo de cartel con respecto al de competencia en ambos segmentos del mercado, lo cual coincide con lo encontrado para OTRAs empresas del mercado. Por otra parte, para el segmento T2, dos distribuciones son levemente asimétricas en el periodo de cartel: Tecnosur y Familia (aunque negativamente, lo cual no coincide con lo previsto por la teoría); mientras que en el periodo de competencia Kimberly y Tecnosur muestran asimetría positiva. En el segmento T4 durante el periodo de cartel, Tecnosur y Kimberly presentan asimetría positiva en sus distribuciones de precios; mientras que se observa asimetría negativa para las mismas empresas durante el periodo de competencia.

Sin embargo, al comparar las distribuciones de los cambios en los precios de Tecnosur con los OTROS competidores, mostrada en la Figura 8, se evidencia que en el segmento T4, no parecen haber diferencias importantes ni en términos de curtosis ni asimetría. Por otro lado, se puede notar una diferencia en términos de curtosis en el segmento T2 durante el periodo del cartel, que parece ser importante.

Con el fin de verificar la robustez y significancia estadísticas de los resultados hasta ahora 
Figura 4: Evolución del comportamiento histórico de los cambios en los precios
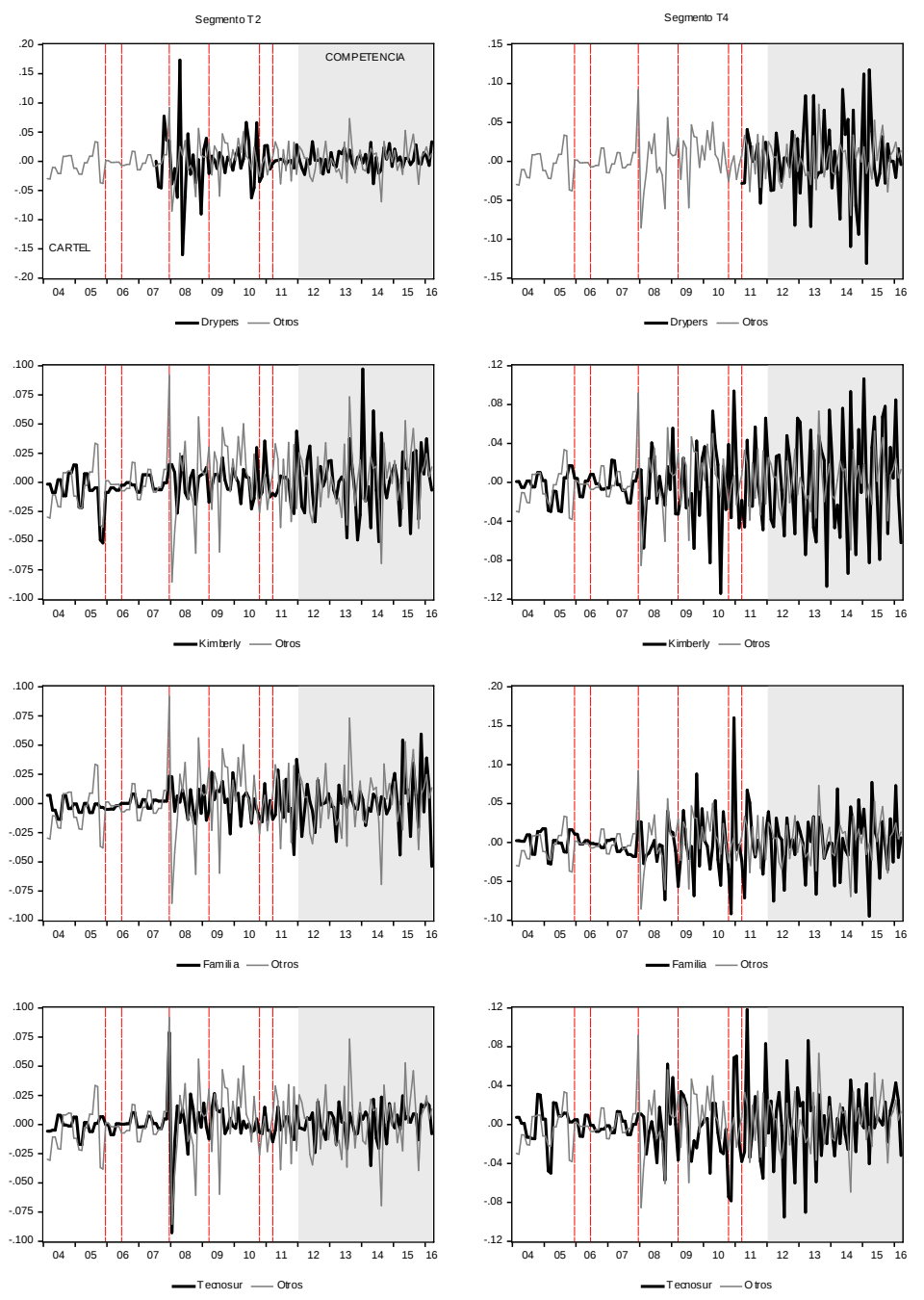

Fuente: Nielsen y OMD. Cálculos del autor. 
Figura 5: Distribución empírica de los cambios en los precios durante el periodo de cartel y pos-cartel

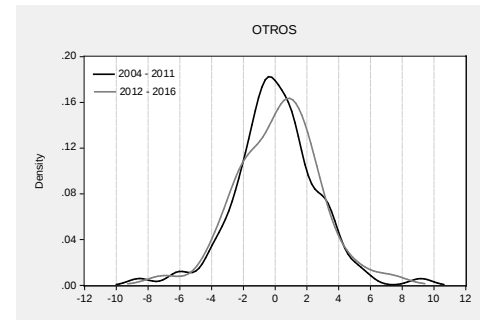

Fuente: Nielsen y OMD. Cálculos del autor.

presentados se presentan los resultados del test de Kolmogorov-Smirnov, el cual permite comparar no paramétricamente dos distribuciones empíricas calculando además los p-valores con el método Bootstrap. El no rechazo de la hipótesis nula permite concluir que las dos muestras provienen de la misma distribución, lo cual en términos económicos implicaría la no existencia de un comportamiento anti-competitivo en el mercado, cuando se comparan los dos sub-periodos. La Tabla 3, panel A, muestra los resultados del test. La hipótesis nula es rechazada en los dos segmentos, excepto en el caso de OTRAs empresas, Drypers en T4 y Familia en T2, lo cual permite concluir que existe evidencia estadística que muestra que la distribución de los cambios en los precios en el periodo de competencia versus el periodo de cartel son diferentes. Sin embargo, y dada el carácter incondicional de este análisis, las diferencias en las distribuciones pueden deberse no exclusivamente a un comportamiento anticompetitivo en el mercado, sino también a choques del mercado ocurridos en cada subperiodo que puedan afectar el comportamiento de los precios. Esto en razón a que las empresas no pueden contralar todas las variables que impactan en un mercado.

Tabla 3: P-valores boostrap para el test de Kolmogorov-Smirnov

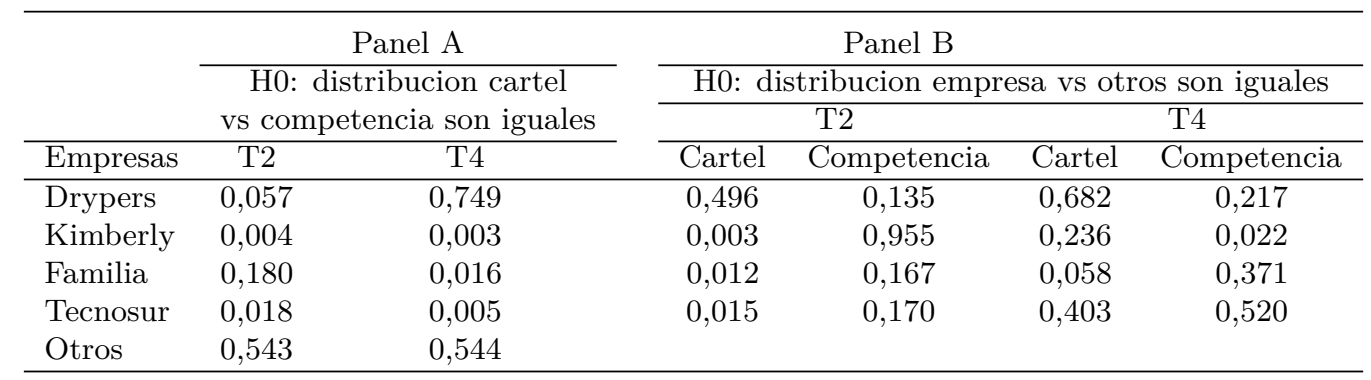

Fuente: Nielsen y OMD. Cálculos del autor. 10.000 iteraciones fueron usadas para el calculo de los p-valores

Adicionalmente, se compara la distribución empírica de los cambios en los precios entre las empresas involucradas en el acuerdo con respecto a las OTRAS empresas. El no rechazo del la hipótesis nula implicaría evidencia estadística para argumentar que, dado el periodo bajo análisis, la distribución de los cambios en los precios provienen de la misma distribución, 
Figura 6: Distribución empírica de los cambios en los precios para el segmento T2 y T4
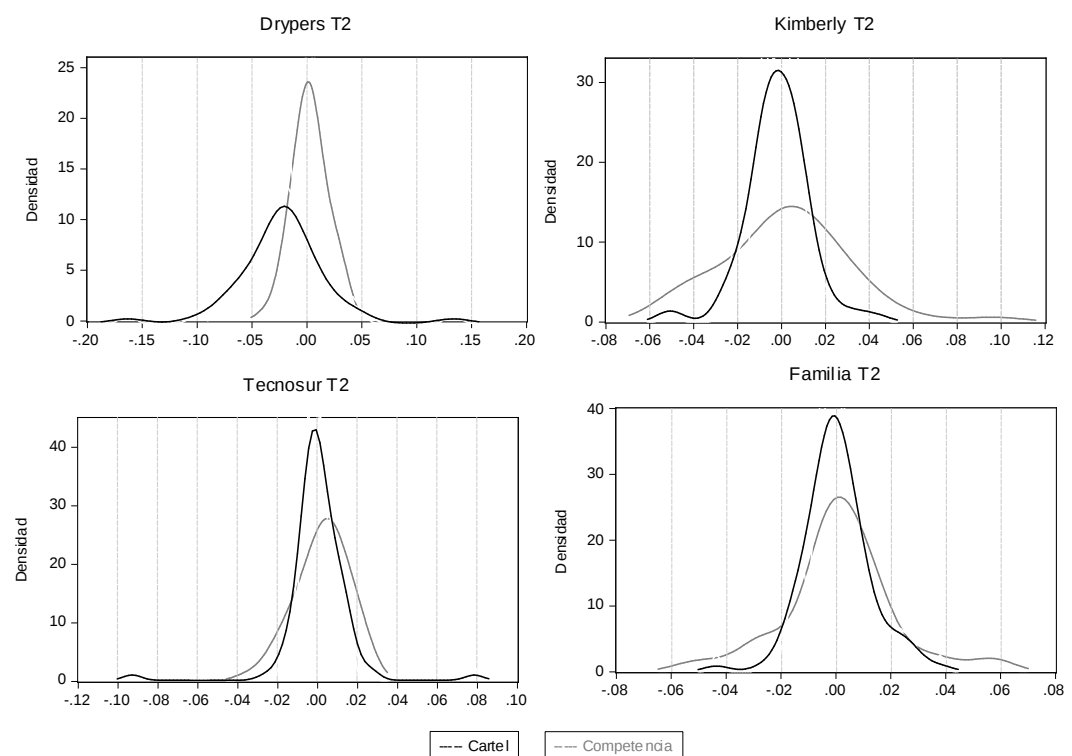

Figura 7: Distribución empírica de los cambios en los precios para el segmento T4
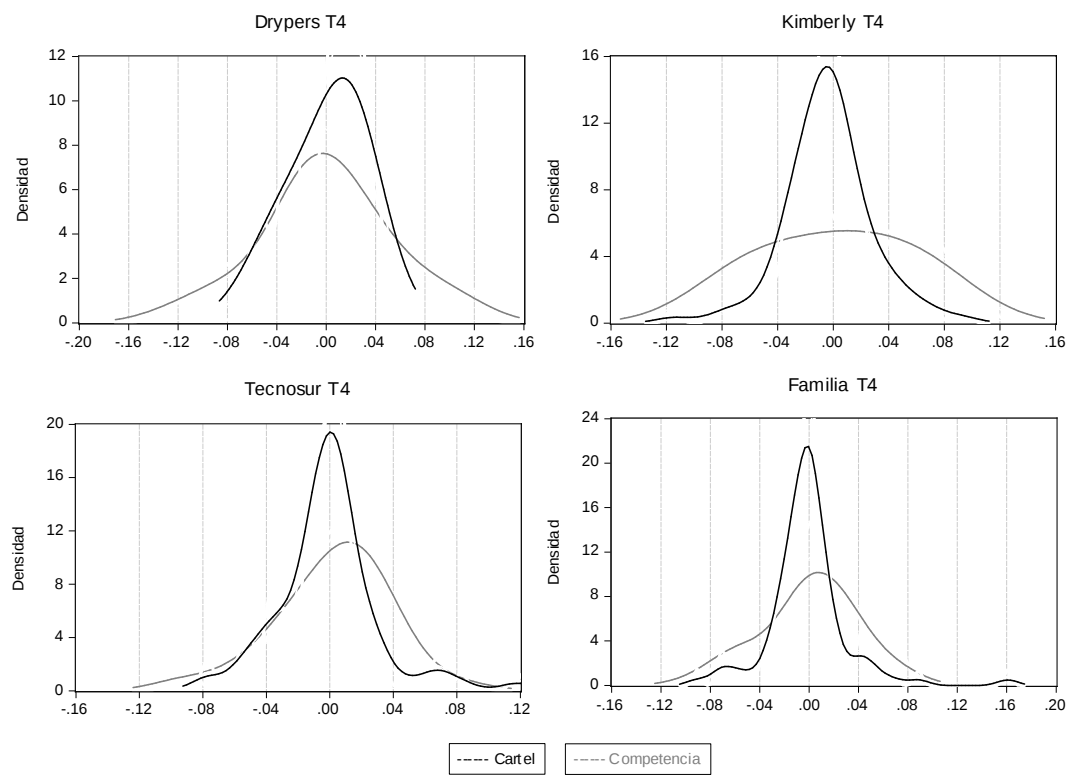

Fuente: Nielsen y OMD. Cálculos del autor. 
Figura 8: Comparación de la distribución empírica de los cambios en los precios: Tecnosur vs Otros
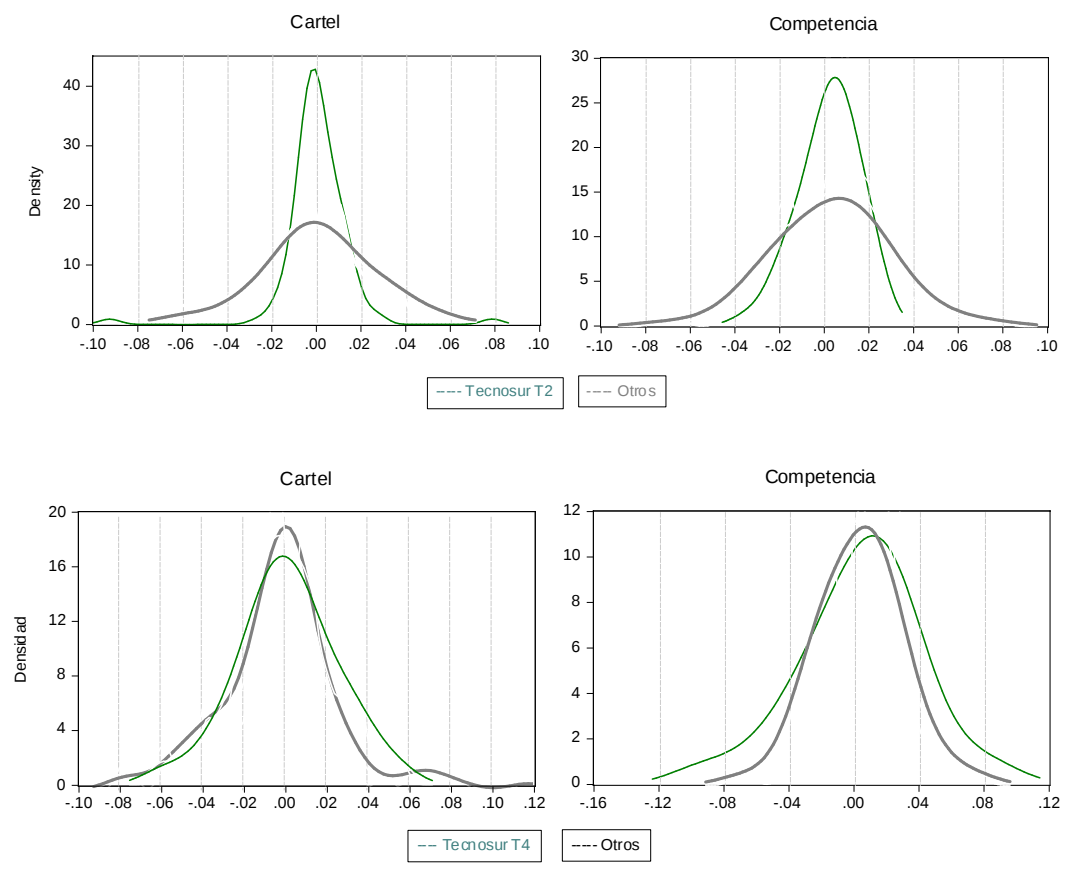

Fuente: Nielsen y OMD. Cálculos del autor.

por lo cual los cambios en los precios no responden principalmente a un comportamiento anticompetitivo, si no a las condiciones o choques de oferta y/o demanda del mercado. La Tabla 3, panel B, muestra los resultados para este test. Para el segmento T2, se rechaza la hipótesis nula por lo que la distribución de los cambios en los precios de cada empresa, exceptuando a Drypers, no provienen de la misma distribución que los cambios en OTROS. Mientras que en el segmento T4, no se rechaza la hipótesis nula, por lo que la distribución de los cambio en los precios de Tecnosur, Kimberly y Drypers provienen de la misma distribución que los cambios en OTROS. Este resultado puede leerse como evidencia de un comportamiento de mercado competitivo en este segmento. Finalmente, no hay evidencia estadística acerca de diferencias en la distribución de los cambios en los precios de cada empresa en el periodo competitivo en ambos segmentos. Esto muestra que efectivamente a partir de 2012 la industria de pañales de bebé ha mostrado un comportamiento competitivo.

En conclusión, no existe evidencia empírica estadísticamente significativa que sugiera un comportamiento anticompetitivo en el segmento T4. En el caso del segmento T2 la evidencia es mixta (en cuanto no hay evidencia de una tendencia de cambios escalonados en los precios ni de una variación en la dispersión de los cambios en los precios, sin embargo hay evidencia de un exceso de curtosis en los cambios en los precios durante el cartel, que lleva al evidenciar diferencias en la distribución de los cambios en los precios entre el periodo de cartel con respecto al periodo de competencia), por lo que no se podría determinar, dado el 
análisis realizado hasta ahora, un patrón en los precios y en sus variaciones que responda a las predicciones teóricas y que permita extraer conclusiones definitivas. Para esto es necesario un análisis que involucre además posibles presiones de oferta y demanda en el mercado.

\subsubsection{Análisis del Comportamiento de los Precios en Relación con Cambios en la Demanda y Oferta del Mercado}

Para este análisis se usa como proxy de la demanda la producción de pañales en el mercado doméstico, representado por el total de ventas de las empresas participantes en el mercado. Como proxy de la oferta se usa el Índice de Producción Industrial para el sector papel y cartón (IPP), el cual mide la evolución mensual de la actividad productiva independientemente del comportamiento de los precios.

La existencia de una correlación entre dos variables no implica causalidad, es decir que una variable se correlacione con otra no implica siempre que una de ellas sea la causa de las alteraciones en los valores de otra. En consecuencia, para explorar las dependencias entre la oferta y los precios, se realizaron pruebas de causalidad de Granger, en los dos sub-periodos. Las pruebas de causalidad en el sentido de Granger permiten determinar si la historia de una variable es útil para tener una mejor predición del comportamiento futuro de la otra, en relación a lo que se obtendría usando sólo la historia propia. La no existencia de dicha capacidad predictiva implica con certeza la no causalidad de una variable hacia la otra, sin embargo este resultado no sería concluyente en el caso contrario. En este sentido, se puede decir que la causalidad en el sentido de Granger es una condición necesaria pero no suficiente para la existencia de verdadera causalidad.

Para la aplicación de este test, se estimó un modelo de Vectores Autoregresivos (VAR) para cada segmento, incluyendo los precios de las empresas en el mercado (exceptuando a Drypers, debido al menor número de observaciones para esta empresa lo que implica la reducción natural de los grados de libertad en la estimación) y el IPP. Con el fin de controlar por el efecto de variables exógenas a los precios de los pañales para bebé, se incluyeron el índice internacional de precios de pulpa de papel como referencia de los costos de los insumos, al igual que la tasa representativa del mercado, el índice de precios al consumidor para alimentos como proxy de las condiciones de demanda exógenas a las empresas de la industria y dummies estacionales. La fuente de información para esta información fue el Banco de la República. El orden de inclusión de las variables de cambios en los precios en el modelo VAR se tomó con base en la participación de mercado de cada una de las empresas (tomando como referencia la información presentada en el Informe Motivado de la SIC): $p_{T, t}, p_{F, t}, p_{K, t}, p_{O, t}$, donde $T$ es Tecnosur, $F$ es Familia, $K$ es Kimberly y $O$ son las otras empresas competidoras del mercado; y finalmente el $I P P_{t}$. Esto con el fin de tener en cuenta el efecto de las empresas grandes sobre las pequeñas en el mercado. ${ }^{15} \mathrm{El}$ orden del rezago del modelo VAR se eligió con bases en los criterios de información discutidos en Lütkepohl (1991), dando como resultado un $\operatorname{VAR}(2)$. Adicionalmente, se verificaron todas las pruebas de ajuste sobre los residuales del modelo: normalidad multivariada, autocorrelación, heterocedasticidad y raices del polinomio característico. Los resultados de la estimación no se presentan aunque están disponibles.

La Tabla 4 muestra los p-valores para la prueba de causalidad de Granger. Para un nivel de significancia del 5\% no se observa ninguna relación causal entre los precios y el IPP en ambas

\footnotetext{
${ }^{15}$ Las pruebas de raíces de Dickey-Fuller aumentadas, KPSS y Phillips y Perron no mostraron evidencia de no estacionariedad en media, al $5 \%$ de nivel de significancia, en las series de cambios en los precios.
} 
Tabla 4: P-valores para la prueba de causalidad de Granger para la oferta

\begin{tabular}{|c|c|c|c|c|c|c|c|c|}
\hline \multirow[b]{3}{*}{ Empresas } & \multicolumn{4}{|c|}{ Competencia } & \multicolumn{4}{|c|}{ Cartel } \\
\hline & \multicolumn{2}{|c|}{ T2 } & \multicolumn{2}{|c|}{$\mathrm{T} 4$} & \multicolumn{2}{|c|}{$\mathrm{T} 2$} & \multicolumn{2}{|c|}{$\mathrm{T} 4$} \\
\hline & Precios & IPP & Precios & IPP & Precios & IPP & Precios & IPP \\
\hline Kimberly & 0,990 & 0,598 & 0,222 & 0,767 & 0,534 & 0,930 & 0,508 & 0,701 \\
\hline Familia & 0,793 & 0,558 & 0,939 & 0,631 & 0,440 & 0,200 & 0,832 & 0,728 \\
\hline Tecnosur & 0,697 & 0,835 & 0,299 & 0,928 & 0,097 & 0,215 & 0,465 & 0,975 \\
\hline Otros & 0,154 & 0,767 & 0,341 & 0,491 & 0,460 & 0,480 & 0,732 & 0,728 \\
\hline
\end{tabular}

Fuente: Nielsen y OMD. Cálculos del autor. La causalidad va de los precios hacia el IPP (columna IPP) y viceversa (columna precios)

direcciones. La única relación causal posible, que se muestra con un nivel de significancia de $10 \%$, está relacionada con el rechazo de la hipótesis nula de que el IPP no causa en el sentido de Granger al precio de Tecnosur, en el segmento T2 durante el periodo de cartel. Sin embargo, el coeficiente asociado al primer rezago de la variable de producción en el modelo VAR es positivo y no se evidencia causalidad en el sentido inverso. En consecuencia, la no existencia de causalidad entre el precio y la oferta del mercado es un patrón que no concuerda con las predicciones asociadas a patrones de mercado bajo un contexto de colusión.

Adicionalmente, se exploró si es posible verificar la existencia de un patrón identificado teóricamente en un equilibrio colusivo que tiene que ver con la rigidez (o insensibilidad) de los precios con respecto a cambios exógenos en la demanda. Dichos cambios en la demanda han sido relacionados con patrones o fluctuaciones estacionales, por lo que se analiza la respuesta relativa de la demanda y de los precios a cambios estacionales (considerados como determinísticos). Para esto se estiman los siguientes modelos Autoregresivos de medias móviles (ARMA) para cada una de los cambios en los precios en cada segmento en el periodo de cartelización:

$$
p_{i, j, t}=c+\alpha_{i, j, 1} p_{i, j, t-1}+. .+\alpha_{i, j, k} p_{i, j, t-k}+\delta_{1} D_{1}+\ldots+\delta_{11} D_{11}+\varepsilon_{i, t}+\beta_{i, j} \varepsilon_{i, t-1}+\ldots+\beta_{i, j, k} \varepsilon_{i, t-k}
$$

en donde $p_{i, t}$ representa el cambio del precio de la $i$ ésima empresa en el segmento $j$ y en el momento $t$ y $D_{1}$ a $D_{11}$ respresentan variables dummy que toman el valor de 1 en el mes 1 y cero en los demas. Finalmente, $\varepsilon_{i, j, t}$ es un ruido aleatorio distribuido de manera normal com media cero y varianza $\sigma_{\varepsilon}^{2}$. Similarmente, el modelo de regresión para los cambios en la demanda total del mercado está dada por:

$$
\text { ventas }_{t}=c+\alpha_{1} \text { ventas }_{t-1}+\ldots .+\alpha_{k} \text { ventas }_{t-k}+\delta_{1} D_{1}+\ldots+\delta_{11} D_{11}+\varepsilon_{t}+\beta_{1} u_{t-1}+\ldots+\beta_{k} u_{t-k}
$$

en donde ventas $s_{t}$ representa el cambio de las ventas en el momento $t$, y $u$ es un ruido aleatorio distribuido de manera normal con media cero y varianza $\sigma_{u}^{2}$

Los resultados de la estimación se muestran en la Tabla 5. Para el análisis se toma como referencia el mes de diciembre, de tal forma que los coeficientes estacionales se interpretan como interceptos por mes, mostrando las diferencias (en términos de magnitud y significancia estadística) en los cambios de los precios en el respectivo mes con respecto a los cambios de precios en diciembre. En el caso de las ventas solo dos parámetros estacionales son estadísticamente significativos, correspondientes a los meses de Marzo y Agosto. Comparando los resultados para los cambios en los precios con respecto a los resultados del modelo para ven- 
tas, se observa que algunos parámetros estacionales son estadísticamente significativos para los precios en los dos segmentos, mientras que no lo son para las ventas. El esquema de precios de las empresas en el mercado muestra una tendencia estacional a la disminución de los precios, que no se corresponde necesariamente con la demanda de mercado. Finalmente, analizando los resultados para las empresas agrupadas en OTROS, las cuales se toman como referencia de un precio competitivo, no existe evidencia estadística que muestre que los precios siguen estrictamente los cambios estacionales de la demanda, por lo que serían igualmente insensibles y/o fijados de manera independiente a los patrones de demanda. Al final de la Tabla 5 se reportan los coeficiente de determinación, Durbin-Watson y los tests de Ljung-Box para probar autocorrelación en los errores del modelo al rezago seis como, pruebas de ajuste de los modelos.

Tabla 5: P-valores para el modelo ARMA de cambio en la demanda

\begin{tabular}{|c|c|c|c|c|c|c|c|c|}
\hline & \multirow[b]{2}{*}{ Demanda } & \multicolumn{3}{|c|}{$\mathrm{T} 2$} & \multicolumn{3}{|c|}{$\mathrm{T} 4$} & \multirow[b]{2}{*}{ Otros } \\
\hline & & Kimberly & Familia & Tecnosur & Kimberly & Familia & Tecnosur & \\
\hline $\mathrm{c}$ & 0,921 & 0,000 & 0,003 & 0,968 & 0,001 & 0,000 & 0,010 & 0,798 \\
\hline Enero & 0,931 & 0,110 & 0,198 & 0,046 & 0,681 & 0,318 & 0,720 & 0,181 \\
\hline Febrero & 0,941 & 0,005 & 0,035 & 0,867 & 0,003 & 0,166 & 0,640 & 0,868 \\
\hline Marzo & 0,023 & 0,002 & 0,006 & 0,774 & 0,002 & 0,022 & 0,163 & 0,783 \\
\hline Abril & 0,204 & 0,005 & 0,143 & 0,888 & 0,023 & 0,005 & 0,179 & 0,412 \\
\hline Mayo & 0,669 & 0,009 & 0,756 & 0,450 & 0,679 & 0,502 & 0,849 & 0,560 \\
\hline Junio & 0,916 & 0,086 & 0,425 & 0,943 & 0,025 & 0,036 & 0,079 & 0,989 \\
\hline Julio & 0,397 & 0,000 & 0,008 & 0,713 & 0,000 & 0,001 & 0,053 & 0,324 \\
\hline Agosto & 0,078 & 0,001 & 0,702 & 0,468 & 0,151 & 0,174 & 0,040 & 0,707 \\
\hline Septiembre & 0,845 & 0,102 & 0,105 & 0,843 & 0,000 & 0,014 & 0,103 & 0,723 \\
\hline Octubre & 0,252 & 0,000 & 0,009 & 0,798 & 0,125 & 0,001 & 0,001 & 0,222 \\
\hline Noviembre & 0,421 & 0,000 & 0,000 & 0,911 & 0,017 & 0,000 & 0,003 & 0,476 \\
\hline Alpha1 & 0,001 & 0,041 & 0,059 & & & & & \\
\hline Beta1 & & & & 0,092 & 0,009 & 0,001 & 0,162 & \\
\hline $\mathrm{R} 2$ & 0,699 & 0,586 & 0,535 & 0,253 & 0,587 & 0,540 & 0,535 & 0,259 \\
\hline DW & 1,865 & 1,809 & 2,119 & 1,967 & 1,902 & 1,954 & 1,977 & 1,956 \\
\hline Ljung-Box(Q6) & 0,968 & 0,224 & 0,193 & 0,189 & 0,212 & 0,867 & 0,194 & 0,388 \\
\hline
\end{tabular}

Fuente: Nielsen y OMD. Cálculos del autor.

Los resultados de la estimación son consistentes con lo que se observa en la Figura 9, la cual muestra las variaciones estacionales en todas las variables bajo análisis. En la gráfica se observa que las ventas no muestran una variación estacional fuerte, lo cual puede derivarse de las características propias del bien en cuestión. Sin embargo, los cambios en los precios muestran una variabilidad estacional más fuerte, lo cual no corresponde al patrón estacional suave de cambios en los precios predicho por la teoría para un esquema colusivo. Adicionalmente, se evidencia la débil relación del esquema de cambios en los precios con las variaciones de la demanda del mercado.

Finalmente, en la Tabla 6 se muestra los p-valores del test de causalidad de Granger para los cambios en los precios en la industria, usando como base el modelo $\operatorname{VAR}(2)$ anteriormente descrito. Cada columna muestra el p-valor para la hipótesis nula de no causalidad de en el sentido de Granger de los cambios en los precios de cada empresa en cada fila hacia la empresa en cada columna. Los resultados muestran que no es posible rechazar la hipótesis nula con un 
Figura 9: Variaciones estacionales de los cambios en los precios y las ventas
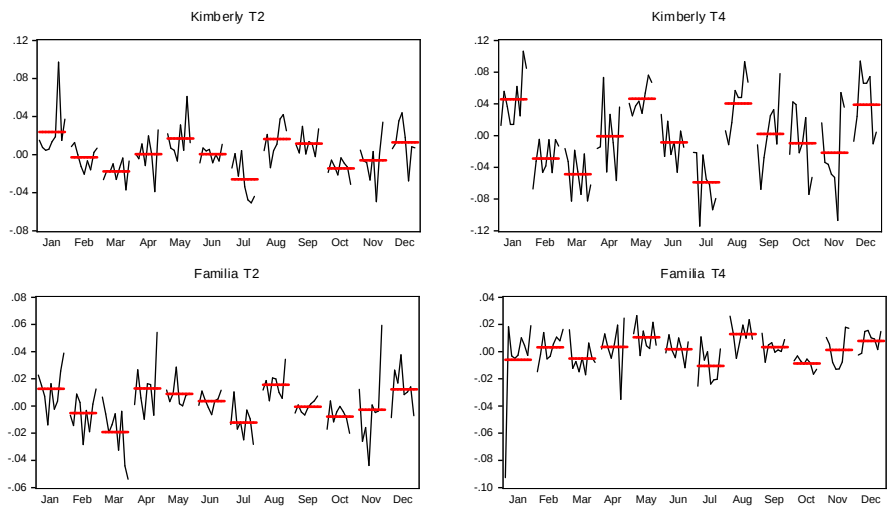

Familia T4
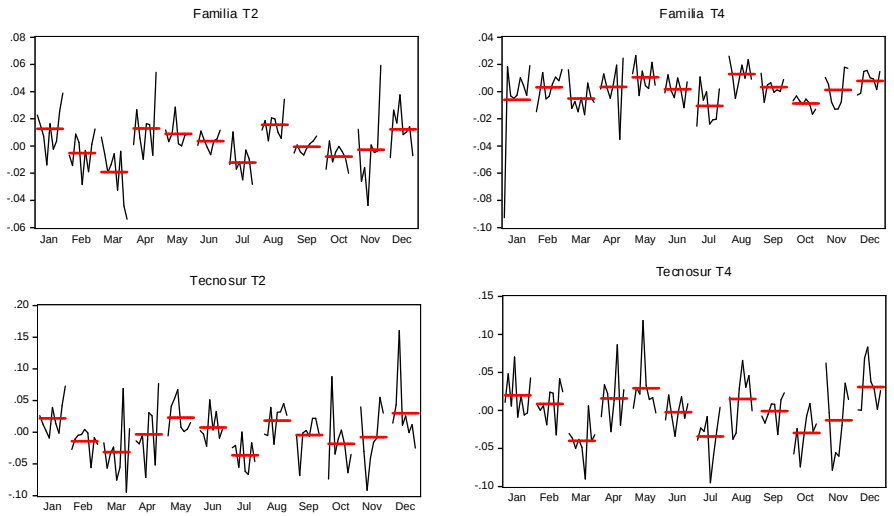

Tecnosur T4
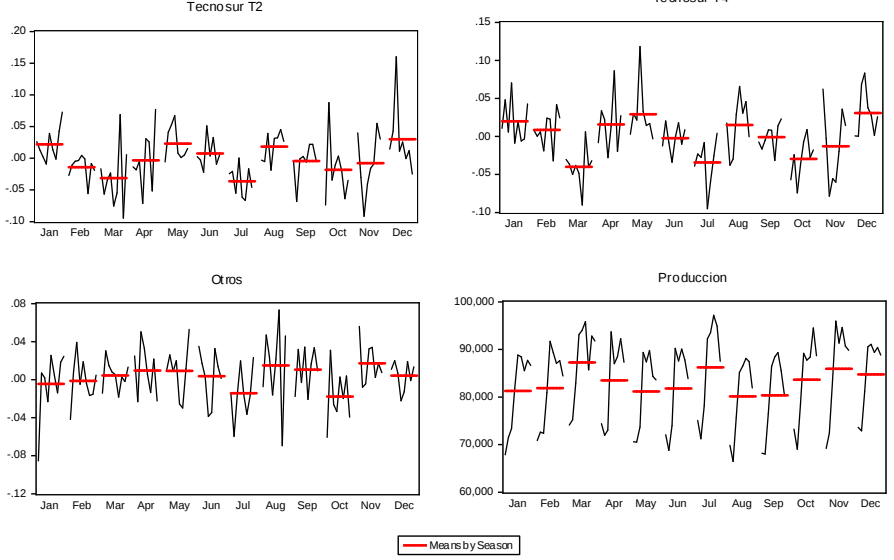

Fuente: Nielsen y OMD. Cálculos del autor.

nivel de significancia del 5\%, por lo que no parece existir una relación causal entre los precios de la industria.

En conclusión, la evidencia en este sentido es nuevamente mixta en tanto no se puede confirmar completamente la hipótesis teórica: no existe una relación negativa entre la oferta y los precios, y los precios muestran variaciones estacionales (principalmente negativas) importantes que no se corresponden con la demanda. En consecuencia, no es posible derivar conclusiones empíricas que sustenten la existencia de patrones teóricamente probados en el caso bajo estudio y, por ende, el impacto de dichos mercados en los precios. Por tanto, se hace necesario explorar comportamientos adicionales identificados por la teoría en el caso de mercados no competitivos por fijación de precios, relacionados con la posible variabilidad condicional de los cambios en los precios. 
Tabla 6: P-valores test de causalidad de Granger entre precios de las empresas

\begin{tabular}{lcccc}
\hline \multicolumn{2}{c}{ Segmento T2 } & & & \\
\hline & Tecnosur & Familia & Kimberly & Otros \\
\hline Tecnosur & & 0,63 & 0,42 & 0,75 \\
Familia & 0,43 & & 0,89 & 0,51 \\
Kimberly & 0,06 & 0,27 & & 0,42 \\
Otros & 0,44 & 0,76 & 0,91 & \\
\hline Segmento T4 & & & & \\
\hline Tecnosur & & 0,23 & 0,35 & 0,58 \\
Familia & 0,99 & & 0,53 & 0,11 \\
Kimberly & 0,28 & 0,92 & & 0,06 \\
Otros & 0,58 & 0,02 & 0,15 & \\
\hline
\end{tabular}

Fuente: Nielsen y OMD. Cálculos del autor. La causalidad va desde las variables en las filas hacia las variables en las columnas.

\subsubsection{Análisis de Cambio Estructural en la Volatilidad de los Precios}

Para el estudio de la segunda predicción, dado que no se conoce con certeza la fecha exacta de fin del periodo de acuerdo de precios, se toman 24 meses antes y 24 meses después de la fecha sugerida en el Informe Motivado como la finalización de los acuerdos, la cual corresponde a diciembre de 2011. Esto con el fin de darle robustez a los resultados obtenidos, en razón a que se presume que los efectos de los acuerdos no desaparecen inmediatamente y se necesita un tiempo de ajuste del mercado, ya que los carteles no pueden controlar todas las fuerzas que influencian un mercado. El objetivo es identificar si hubo un cambio en la estructura de la volatilidad de los precios como resultado de la finalización del comportamiento colusivo. Si no existe evidencia que muestre el posible cambio estructural, no habrá evidencia empírica concluyente acerca del efecto del cartel en los precios.

La Figura 10 no muestra que se haya producido hacia finales de 2011 e inicios de 2012 un cambio abrupto en el comportamiento de los cambios en los precios en ninguna de los segmentos bajo análisis. Adicionalmente, observa que la volatilidad de los precios de las empresas bajo investigación en el segmento T4 fue mayor que la de los precios de las Otras empresas. Para el segmento T2, la volatilidad de los precios resulta muy similar entre empresas, sin una evidencia contundente de cambio estructural en las mismas alrededor de diciembre de 2011.

Dada la falta de evidencia clara que se derive de los datos, y de acuerdo con lo propuesto por la literatura, se estima el proceso de varianza condicional de los precios usando modelos ARMA-GARCH introducidos por Engle (1982) y Engle y Bollerlev (1986). Estos modelos permiten examinar conjuntamente el comportamiento de la media y la varianza de los precios durante las fases de colusión y competencia. La especificación de los modelos ARMA(1,1)$\operatorname{GARCH}(1,1)$ estimados es la siguiente:

$$
\begin{gathered}
p_{i, j, t}=a_{i, j} p_{i, j, t-1}+d_{i, j} D+\varepsilon_{i, j, t}+b_{i, j} \varepsilon_{i, j, t-1} \\
\sigma_{i, j, t}^{2}=\omega_{i, j}+\delta_{i, j} D+\alpha_{i, j} \varepsilon_{i, j, t}^{2}+\beta_{i, j} \sigma_{i, j, t-1}^{2}
\end{gathered}
$$

donde $p_{i, t}$ representa el precio de la $i$ ésima empresa ( $i=$ Kimberly, Familia, Tecnosur, OTROS) en el segmento $j$ ( $j=$ Tier 2, Tier 4 ) en el momento $t$, y $\varepsilon_{i, j, t}$ es un ruido aleatorio distribuido 
Figura 10: Comportamiento histórico de los cambios en los precios 2008-2016
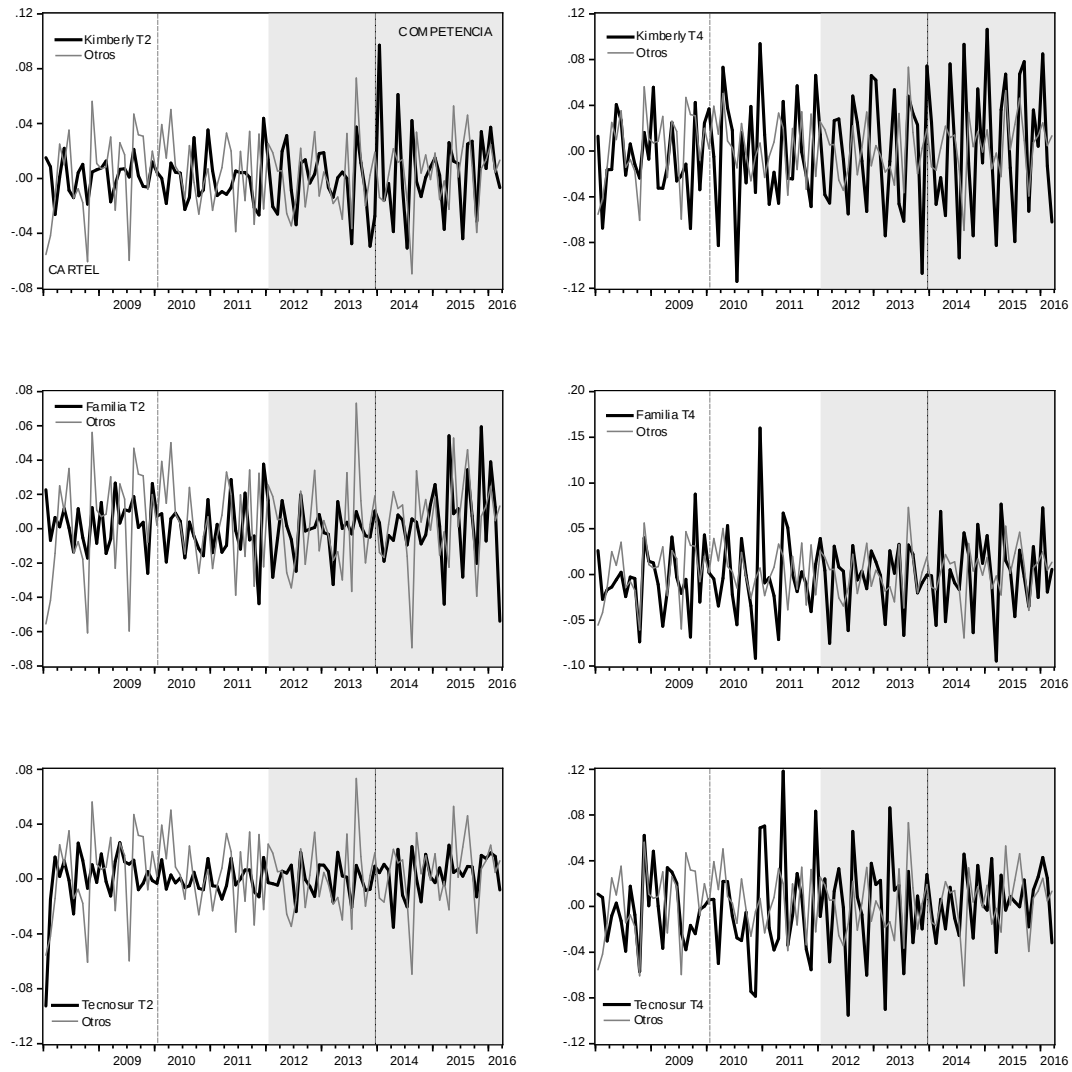

Fuente: Nielsen y OMD. Cálculos del autor.

Normal con media cero y varianza $\sigma_{t}^{2}$ que sigue un proceso condicional definido en la ecuación (4). $\omega, \alpha \geq 0$ y $\beta \geq 0$ son parámetros que aseguran que la varianza sea positiva; $a$ y $b$ son los parámetros autoregresivo y de medias móviles para el proceso de media condicional de los precios, los cuales deben ser menores que 1 para garantizar la estacionariedad del modelo. $D$ es una variable dummy que toma un valor de 0 durante el periodo de acuerdo de precios y 1 durante el periodo de competencia, y $d$ y $\delta$ son coeficientes asociados a ésta en la ecuación de media y varianza condicionales.

La introducción de la variable dummy tanto en la ecuación de la media como en la ecuación de la varianza se hace con el fin de testear si existe un cambio estructural (determinístico) en la media del precio y su varianza, que se corresponda con paso del periodo de cartel al periodo de competencia. Dado que variable dummy toma un valor de 0 durante el periodo de acuerdo de precios y 1 durante el periodo de competencia, la significancia estadística de esta variable dará evidencia empírica de un cambio en la media y/o en la varianza de los precios del periodo de competencia en relación al periodo de cartel.

La Tabla 7 muestra los resultados de la regresión que fueron estimados usando el com- 
Tabla 7: P-valores para el modelo ARMA-GARCH

\begin{tabular}{|c|c|c|c|c|c|c|c|}
\hline & \multicolumn{3}{|c|}{$\mathrm{T} 2$} & \multicolumn{3}{|c|}{$\mathrm{T} 4$} & \multirow[b]{2}{*}{ Otros } \\
\hline & Kimberly & Familia & Tecnosur & Kimberly & Familia & Tecnosur & \\
\hline \multicolumn{8}{|l|}{ Media } \\
\hline dummy & 0,986 & 0,768 & 0,830 & 0,067 & 0,611 & 0,398 & 0,061 \\
\hline $\operatorname{ar}(1)$ & & 0,000 & 0,000 & 0,000 & 0,000 & 0,000 & 0,000 \\
\hline $\operatorname{ma}(1)$ & 0,000 & 0,007 & 0,000 & & & & \\
\hline dummy x $\operatorname{ar}(1)$ & & & & 0,000 & & & \\
\hline \multicolumn{8}{|l|}{ Varianza } \\
\hline $\mathrm{c}$ & 0,701 & 0,370 & 0,238 & 0,000 & 0,000 & 0,000 & 0,000 \\
\hline $\operatorname{ar}(1)$ & 0,019 & & 0,000 & 0,021 & 0,000 & 0,084 & 0,000 \\
\hline $\operatorname{ma}(1)$ & 0,000 & 0,000 & 0,000 & & 0,000 & & 0,661 \\
\hline dummy & 0,108 & 0,960 & 0,103 & 0,267 & 0,029 & 0,224 & \\
\hline $\mathrm{R} 2$ & 0,143 & 0,382 & 0,567 & 0,117 & 0,054 & 0,324 & 0,492 \\
\hline DW & 2,211 & 1,904 & 2,144 & 1,893 & 2,110 & 1,770 & 1,755 \\
\hline Ljung-Box (Q6) & 0,145 & 0,068 & 0,241 & 0,097 & 0,303 & 0,019 & 0,150 \\
\hline Ljung-Box2 (Q6) & 0,417 & 0,995 & 0,104 & 0,502 & 0,868 & 0,884 & 0,556 \\
\hline
\end{tabular}

Fuente: Nielsen y OMD. Cálculos del autor.

ponente cíclico de los precios obtenido a partir de Hodrick y Prescott (con el fin de tener series estacionarias), evidenciándose dos resultados fundamentales: primero la necesidad de un modelo dinámico de heterocedasticidad condicional para la modelar los precios de los pañales. En particular, se evidencia que el comportamiento de los precios en el momento actual responde a una expectativa generada sobre el valor de cambio producido en el momento precedente; es decir a un valor esperado condicionado por la varianza del período anterior. En consecuencia, la estimación de la variación en los precios a través de la desviación estándar de los precios resulta inadecuada para el análisis. Segundo, los coeficientes estimados para la variable dummy en la ecuación para la media de los precios solo resultó estadísticamente significativa, aunque a un nivel de significancia del 10\%, para Kimberly en el segmento T4 con un valor de 12,41. El coeficiente para la interacción entre la variable dummy y el precio rezagado un periodo, el cual es estadísticamente significativo, fue igual a - 0,4 ; lo cual indica que los cambios en los precios de competencia variaron en promedio en un $12 \%$ mientras que en colusión variaron en un $12,5 \%$. En consecuencia, mientras el precio en competencia presentaba variaciones promedio de $\$ 68$ pesos por unidad, en colusión dichas variaciones fueron en promedio de $\$ 71$ pesos. Este resultado no evidenciaría una diferencia importante en la variación media de los precios en ambos periodos; sin embargo, estos valores son superiores a las desviaciones estándar presentadas en la Tabla 8, que muestra la estadística descriptiva del componente cíclico de los precios en ambos subperiodos.

En la ecuación de la varianza condicional, la variable dummy para Familia en el segmento T4 con una probabilidad del 3\%. Esto indica diferencias estadísticamente significativas en la variabilidad de los cambios en los precios entre el periodo de competencia versus colusión para empresas. Sin embargo, el coeficiente estimado es igual a -9,64, lo cual mostraría que la variabilidad de los cambios en los precios fue menor en competencia que en colusión, lo cual no está de acuerdo con las predicciones teóricas. Sin embargo, este resultado está en la misma dirección de las estadísticas descriptivas de la Tabla 8. Al final de la Tabla 4, se 
Tabla 8: Estadística descriptiva para la serie de precios destendencializada.

\begin{tabular}{lccccccc}
\hline & \multicolumn{2}{c}{ Kimberly } & \multicolumn{2}{c}{ Familia } & \multicolumn{2}{c}{ Tecnosur } & \multirow{2}{*}{ Otros } \\
\cline { 2 - 7 } & $\mathrm{T} 2$ & $\mathrm{~T} 4$ & $\mathrm{~T} 2$ & $\mathrm{~T} 4$ & $\mathrm{~T} 2$ & $\mathrm{~T} 4$ & \\
\hline Meadia & 0,238 & $-0,651$ & 1,060 & $-0,062$ & 0,821 & $-1,314$ & 1,195 \\
Mediana & $-0,324$ & 2,028 & 1,136 & 3,638 & $-1,232$ & $-1,329$ & $-1,083$ \\
Max & 1,517 & 4,659 & 1,983 & 3,594 & 2,064 & 5,949 & 2,738 \\
Min & $-2,159$ & $-4,382$ & $-1,958$ & $-5,822$ & $-1,904$ & $-8,210$ & $-3,093$ \\
Std. Dev. & 7,172 & 2,149 & 9,723 & 1,920 & 9,012 & 2,678 & 1,382 \\
Asimetría & $-0,306$ & $-0,019$ & $-0,116$ & $-0,947$ & 0,241 & $-0,553$ & 0,017 \\
Curtosis & 3,254 & 2,428 & 2,441 & 3,965 & 2,264 & 3,839 & 2,750 \\
Jarque-Bera & & & & & & & \\
p-valor & 0,645 & 0,720 & 0,693 & 0,011 & 0,461 & 0,145 & 0,938 \\
\hline
\end{tabular}

Fuente: Nielsen y OMD. Cálculos del autor.

reportan el coeficiente de determinación, el Durbin-Watson y los tests de Ljung-Box para probar autocorrelación en los errores y los errores al cuadrado del modelo al rezago 6 .

En segundo lugar, y usando el proceso de varianza condicional extraído de la modelación anterior, se hace un análisis que permita identificar los posibles momentos de cambio en la varianza de los precios, en lugar de testear a priori una fecha para los mismos. La detección de cambios estructurales confirmará o no el efecto de los acuerdos en los precios. Para esto se usa el test estadístico de Quandt-Andrews para cambio estructural cuando no se conoce el momento del cambio, usando la especificación del modelo GARCH obtenido para cada serie en la Tabla 7.

Tabla 9: P-valores y fechas por el test de Quandt-Andrews para cambio estructural

\begin{tabular}{llllll}
\hline \multicolumn{5}{c}{ Hipotesis nula: No cambios estructurales } & $(15 \%$ trimmed datos $)$ \\
\hline \multirow{2}{*}{ Empresas } & Test & \multicolumn{3}{c}{ T2 } & T4 \\
\cline { 2 - 5 } Kimberly & Maximum LR F-statistic & $(2014 \mathrm{M} 02)$ & 0,004 & $(2014 \mathrm{M} 09)$ & 0,352 \\
& Maximum Wald F-statistic & $(2009 \mathrm{M} 06)$ & 0,000 & $(2009 \mathrm{M} 10)$ & 0,012 \\
\multirow{3}{*}{ Familia } & Maximum LR F-statistic & $(2015 \mathrm{M} 01)$ & 0,528 & $(2010 \mathrm{M} 12)$ & 0,000 \\
& Maximum Wald F-statistic & $(2014 \mathrm{M} 06)$ & 0,029 & $(2012 \mathrm{M} 11)$ & 0,000 \\
& Maximum LR F-statistic & $(2014 \mathrm{M} 05)$ & 0,000 & $(2011 \mathrm{M} 01)$ & 0,150 \\
& Maximum Wald F-statistic & $(2014 \mathrm{M} 02)$ & 0,000 & $(2013 \mathrm{M} 08)$ & 0,000 \\
\hline Otros & Maximum LR F-statistic & $(2014 \mathrm{M} 09)$ & 0,000 & & \\
\hline & Maximum Wald F-statistic & $(2009 \mathrm{M} 11)$ & 0,000 & & \\
\hline
\end{tabular}

Fuente: Nielsen y OMD. Cálculos del autor.

La Tabla 9 presenta los resultados del test Quandt-Andrews, el cual ofrece tanto la estimación del momento del cambio estructural como la significancia estadística del mismo. La hipótesis nula es que no existen cambios estructurales (considerando los datos una vez se han eliminado las observaciones pertenecientes al 15\% superior e inferior de la distribución). Como se puede observar en la Tabla los cambios estructurales identificados no corresponden al periodo de finalización del acuerdo de precios en ninguno de los dos segmentos. En el 
segmento T2 se identificó un cambio estructural en el primer semestre de 2014 que parece ser común en las empresas. Este cambio coincide con un periodo de devaluación del peso el cual impacto los costos de los insumos de producción de la industria, mientras que en el segmento T4 no se identifica una fecha común a las empresas ni tampoco un cambio a finales de 2011 principios de 2012.

De este análisis se puede concluir que no existe evidencia empírica que muestre un cambio estructural en la variabilidad de los precios en ninguno de los segmentos analizados. Por ende, no parece cumplirse una de las predicciones teóricas fundamentales de la literatura sobre colusión, discutida desde la primera contribución de Stigler (1964) y ampliamente usada por las autoridades de la competencia para la deteción de los efectos de un cartel en un mercado, según la cual la detección de un cartel hace que las empresas implicadas cambien abruptamente sus precios, generando un cambio estructural en las series.

Finalmente, y dada la evidencia estadística conjunta derivada de las tres sub-secciones anteriores, se podría pensar que aún en presencia de una cartelización de empresas en el mercado de pañales para bebé en Colombia, no se puede hallar evidencia de efectos sobre el mercado y, en particular, sobre los precios. La imposibilidad para haber ejecutado el acuerdo y alcanzar el resultado colusivo en la práctica puede ser resultado de las dificultades que enfrentan las empresas envueltas en acuerdos de precios en términos de coordinación, negociación e implementación de dichos acuerdos de una manera efectiva en el mercado. Así mismo, es muy probable que uno o varios miembros del cartel se hayan desviado en la práctica del acuerdo, tal como lo predice la teoría (Porter (1983), Green y Porter (1984), Rotemberg y Saloner (1986), Ellison (1994)).

4.4 Poder de Mercado y Presiones Competitivas en la Industria de Pañales: Un Análisis Estructural

El objetivo de esta sección es estimar los márgenes de rentabilidad de la industria de pañales con base en su estructura actual y datos del mercado (ventas y precios), y compararlos con los resultados de mercado que se obtendrían bajo estructuras alternativas (hipotéticas) de oferta. En particular, se evalúan escenarios contrafactuales de competencia más intensa, por un lado, y mayor concentración del mercado, por otro lado.

\subsubsection{La oferta: un modelo de competencia oligopolística}

Suponga que en el mercado de pañales para niños hay $j=1, \ldots, J$ variedades $^{16,17}$ de pañales. Suponga que en este mercado hay $F$ empresas y que cada una produce un subconjunto, $\mathscr{F}_{f}$ de las $J$ marcas distintas de pañales. Los beneficios de la empresa $i$ están dados por

$$
\Pi_{f}=\sum_{j \in \mathscr{F}_{f}}\left(p_{j}-c m_{j}\right) M s_{j}(p)-C_{f}
$$

donde $s_{j}(p)$ es la parte de mercado de la marca $j$, la cual es una función de los precios de

\footnotetext{
${ }^{16}$ Para efectos de este modelo, una variedad de pañal se define como una combinación entre una categoría de pañal (tier 1,2,3,4 o 5) de una marca comercial particular de las que existen en el mercado. Por ejemplo, el pañal Winny-tier 2 producido por Tecnosur es una variedad distinta al pañal Winny-tier 4 de Tecnosur.

${ }^{17}$ En adelante, se utilizarán indistintamente los términos 'marca' y 'variedad' para hacer referencia a los productos incluídos en el análisis.
} 
todas las marcas, $M$ es el tamaño del mercado de pañales, y $C_{f}$ es el costo fijo de producción que enfrenta la empresa $f$. Suponiendo que un equilibrio de Nash-Bertrand en precios en estrategias puras existe, y que los precios que soportan tal equilibrio son estrictamente positivos, el precio $p_{j}$ de alguna variedad $j$ producida por la empresa $f$ debe satisfacer las condiciones de primer orden del problema de maximización del beneficio de la empresa:

$$
s_{j}(p)+\sum_{l \in \mathscr{F}_{f}}\left(p_{l}-c m_{l}\right) \frac{\partial s_{l}(p)}{\partial p_{j}}=0 .
$$

Se tiene entonces un sistema de $J$ ecuaciones, una por cada marca producida en el mercado. Este sistema permite recuperar márgenes del precio final que paga el consumidor sobre el costo marginal de producción para cada variedad, mediante la resolución del sistema de ecuaciones. Para este efecto, definamos el sistema de ecuaciones de primer orden en forma matricial, de la siguiente manera:

$$
s(p)-\Omega(p-c m)=0,
$$

donde $s(\cdot), p$ y $\mathrm{cm}$ son vectores de dimensión $J \times 1$, de partes de mercado, precios y costos marginales, respectivamente; $\Omega$ es una matriz de dimensión $J \times J$ que contiene los efectos marginales de un cambio en el precio de un bien sobre las partes de mercado de cada uno de los productos de la empresa $f$. En términos formales, la entrada de la fila $j$ y la columna $l$ de esta matriz, para todo $j, l=1, \ldots, J$, se define como:

$$
\Omega_{j l}=d_{j l} * S_{j l}
$$

con

$$
S_{j l}=-\frac{\partial s_{l}}{\partial p_{j}}, \quad d_{j l}=\left\{\begin{array}{cc}
1, & \text { si } \exists f:\{l, j\} \subset \mathscr{F}_{f} \\
0, & \text { en otro caso, }
\end{array}\right.
$$

$d_{j l}$ define la estructura de propiedad de marcas por parte de empresas de la industria. Así, si $j$ y $l$ son marcas producidas por $f$, la matriz tendrá 1 como entrada, de lo contrario la matriz tendrá un cero en 0 esa posición. Resolviendo el sistema de ecuaciones para el vector de márgenes (que se define como la diferencia entre el vector de precios y el de costos marginales, se obtiene:

$$
p-c m=\Omega^{-1} s(p) .
$$

Siguiendo a Nevo (2001), los márgenes de precio sobre costo (MPC) marginal que aparecen en la ecuación (10) pueden ser estimados sin necesidad de conocer los costos marginales de la industria, mediante la estimación de la demanda de este mercado. Dicha estimación, que se hará teniendo en cuenta la estructura actual de la industria descrita anteriormente ${ }^{18}$ servirá de base para determinar qué tan competitiva ha sido esta industria en el período de estudio (20042015). Para esto, se comparan los márgenes obtenidos con cuatro estructuras hipotéticas de

\footnotetext{
${ }^{18}$ Constituída por empresas multiproducto, que producen distintas variedades de pañal (básicamente diferenciadas en términos de calidad en cinco categorías o 'tiers'), con mayor presencia de las tres empresas líderes (Kimberly, Familia y Tecnosur) pero con participación de otras marcas comerciales (Procter and Gamble, Johnson \& Johnson, y marcas importadas) y marcas propias de supermercado.
} 
oferta para esta industria: la primera, corresponde a un escenario de empresas uniproducto en el que cada competidor produce una única variedad de pañales de la gama de variedades disponible en el mercado, lo que implica que habría tantas empresas como variedades de pañal y cada una se ocupa de maximizar el beneficio que le reporta la única "marca" que produce. La segunda, corresponde a una estructura en la una de las empresas líderes del mercado (Kimberly) controla totalmente las decisiones de una segunda empresa (Tecnosur) mientras los otros productores siguen siendo sus rivales. ${ }^{19} \mathrm{El}$ tercer escenario corresponde a un mercado más concentrado en el que las tres empresas líderes (Kimberly, Familia y Tecnosur) se fusionan en una gran empresa que controla las tres marcas (Huggies, Pequeñín y Winny) ${ }^{20}$ Finalmente, el cuarto escenario corresponde a una estructura de monopolio o colusión perfecta de precios en los que una única empresa controla todas las marcas del mercado. Todos estos escenarios se simulan alterando la estructura de propiedad de las marcas, $\mathscr{F}_{f}$, y la matriz de propiedad, $D$.

\subsubsection{La demanda de pañales}

El modelo que se expone a continuación es estándar en la literatura económica que estudia las elecciones de los consumidores desde una perspectiva empírica. Es un modelo de elección discreta con coeficientes aleatorios en el que la demanda del consumidor final se deriva de la especificación empírica de sus preferencias como una función de variables observables, tales como las características del producto y su precio, y de variables no observables que conjuntamente determinan la preferencia idividual de un producto específico sobre las demás alternativas.

Considere un mercado con $I$ consumidores denotados por el subíndice $i=1,2, \ldots, I$. En este contexto, un mercado se definirá como una combinación entre un bimestre y una región geográfica del territorio colombiano. La utilidad indirecta condicional que el consumidor $i$ obtiene de la compra del producto $j$ en el mercado $t$ está dada por

$$
u_{i j t}=\beta_{0 i}+x_{j} \beta_{1}-\alpha_{i} p_{j t}+\xi_{j}+\Delta \xi_{j t}+\epsilon_{i j t}
$$

con $x_{j}$ que representa las características observables del producto $j$ comunes en todos los mercados, $p_{j t}$ es el precio unitario del producto $j$ en el mercado $t, \xi_{j}$ captura la valoración media (sobre individuos y tiempo) de las características no observables (por parte del econometrista) del producto, y $\Delta \xi_{j t}=\xi_{j t}-\xi_{j}$ que captura las desviaciones específicas a cada mercado local de la media nacional bajo el supuesto que en cada mercado las personas valoran de manera diferente las características del producto. Finalmente, el modelo captura preferencias heterogéneas entre individuos distintos de dos formas: 1) mediante la inclusión de un choque aleatorio de utilidad, aditivamente separable del resto de los determinantes de la utilidad y

\footnotetext{
${ }^{19}$ Este escenario pretende capturar la situación en la que Kimberly era propietaria del $50 \%$ de Tecnosur (1998-2014), pero llevada al extremo hipotético de una integración entre estas dos empresas, es decir, Kimberly sería el propietario de Tecnosur y controlaría completamente la marca Winny en este período.

${ }^{20}$ Este escenario pretende evaluar la situación investigada por la Superintendencia de Industria y Comercio en el "Caso Pañales" (Resolución SIC No. 47965 de 2014; Informe Motivado No. 13-266923 de 2016) en el que estas tres empresas presuntamente se coordinaron para implementar "prácticas comerciales restrictivas de la competencia" (SIC, 2014). Este escenario de integración empresarial equivaldría a un caso de colusión perfecta en el que tres empresas logran coordinarse para fijar precios de sus productos y maximizar el beneficio conjunto.
} 
de media cero, $\epsilon_{i j t}$, que es estándar en la literatura de modelos de elección discreta; y 2) por medio de la interacción de características de cada individuo con las características de los productos, a través de parámetros específicos a cada individuo $\left(\alpha_{i}, \beta_{0 i}\right)$. Estos coeficientes capturan valoraciones individuales marginales del precio y características de los productos (frente a productos alternativos a pañales desechables) y son modelados como funciones de características demográficas no observables:

$$
\left(\begin{array}{c}
\alpha_{i} \\
\beta_{0 i}
\end{array}\right)=\left(\begin{array}{c}
\alpha \\
\beta_{0}
\end{array}\right)+\Sigma v_{i}, \quad v_{i} \sim N\left(0, I_{2}\right)
$$

donde $\alpha$ y $\beta_{0}$ son coeficientes comúnes a todos los individuos que capturan las preferencias medias de la población por el precio y las características de los productos, y $\Sigma$ es una matriz cuyas entradas capturan la desviación estándar de las preferencias individuales con respecto a dichas medias.

Este modelo es consistente con el hecho de que no todas las marcas disponibles en el mercado están incluidas en este modelo, o que los individuos no consumen pañales únicamente sino que eligen otros bienes o, en algunas ocasiones, deciden no comprar nada. Para capturar esto, se define una opción "externa" alternativa a las $J$ opciones incluidas en el conjunto de elección del mercado en estudio y cuya utilidad media se normaliza a cero. En este orden de ideas, la utilidad indirecta de la opción externa está determinada por $u_{i 0 t}=\epsilon_{i 0 t}$.

Un supuesto clave de este modelo es que cada individuo $i$ elige máximo una unidad del producto que le brinda la mayor utilidad posible frente a todas las alternativas disponibles, cada vez que lo consume. ${ }^{21}$ Formalmente, $i$ elige $j$ en $t$ si y solo si:

$$
u_{i}\left(p_{j t}, x_{j}, \xi_{j}, \Delta \xi_{j t}, \epsilon_{i j t}\right) \geqslant u_{i}\left(p_{l t}, x_{l}, \xi_{l}, \Delta \xi_{l t}, \epsilon_{i l t}\right), l=1, \ldots, J .
$$

Como $\epsilon_{i j t}$ es una variable aleatoria no observada, se debe asumir una distribución de probabilidades para que la estimación del modelo sea factible. Suponga que se distribuye idéntica e independientemente según la función de Valor Extremo Tipo 1. Este supuesto permite expresar la participación de mercado de cada marca (la proporción de individuos que prefieren la marca $j$ sobre las demás) como una función de los niveles medios de utilidad de las $J+1$ alternativas, de la siguiente manera:

$$
s_{j t}=\int \frac{\exp \left(\beta_{0 i}+x_{j} \beta_{1}-\alpha_{i} p_{j t}+\xi_{j}+\Delta \xi_{j t}\right)}{1+\sum_{l=1}^{J} \exp \left(\beta_{0 i}+x_{l} \beta_{1}-\alpha_{i} p_{l t}+\xi_{l}+\Delta \xi_{l t}\right)} d F(v)
$$

donde $F(\cdot)$ denota una función de distribución poblacional. Este modelo de demanda implica que la elección del consumidor está determinada tanto por factores comunes a todos los individuos que consumen el bien (es decir, que no varían de individuo a individuo) como por factores individuales que determinan la preferencia por una característica o marca particular que otros no encuentran tan atractiva. Reescribiendo la función de utilidad como función de

\footnotetext{
${ }^{21}$ Este supuesto garantiza que un individuo no combina unidades (o porciones de una unidad) de diferentes variedades en una sola ocasión de consumo. Este supuesto es absolutamente consistente con la forma en la que los individuos usan los pañales para sus bebés: utilizan uno a la vez cada vez que necesitan cambiar a su bebé de pañal (utilizar dos variedades distintas al mismo tiempo o mitad de cada una de dos marcas no es posible para este tipo de productos).
} 
estos dos componentes tenemos que:

$$
u_{i j t}=\delta_{j t}\left(p_{j t}, x_{j}, \xi_{j}, \Delta \xi_{j t} ; \alpha, \beta_{0}, \beta_{1}\right)+\mu_{i j t}\left(p_{j t}, x_{j}, v_{i} ; \sigma\right)+\epsilon_{i j t}
$$

donde $\delta_{j t}$ es la parte de la utilidad que es común a todos los individuos o "utilidad media" y $\mu_{i j t}+\epsilon_{i j t}$ es una desviación idiosincrática de dicha media; $\sigma$ es un vector que contiene los parámetros de la matriz $\Sigma$, esto es, $\sigma=\operatorname{vec}(\Sigma)$. Usando esta expresión de la utilidad, (13) se puede expresar como una función de la utilidad media, otras variables observables y parámetros: $s_{j t}\left(x, p_{t}, \delta_{t} ; \sigma\right)$.

\subsubsection{Implementación empírica}

Como se mencionó anteriormente, los márgenes y costos marginales de cada productor se pueden obtener mediante la modelación y estimación adecuada de la demanda del mercado con base en datos recolectados de la actividad del mercado. Esta sección explica con detalle cómo el modelo estructural de demanda es llevado a los datos, cómo se estiman los parámetros del modelo que dan forma a la función de utilidad presentada anteriormente y cómo, después de obtener dichas estimaciones, se pueden calcular los MPC bajo diferentes escenarios de oferta.

\section{a) Adaptación de los datos}

La estimación del modelo presentado anteriormente requiere observar precios finales al consumidor y cantidades vendidas a nivel de marca para una muestra de todo el conjunto de productos ofrecidos a los consumidores en el mercado, idealmente con suficiente variación entre zonas geográficas y tiempo. Los datos de Nielsen descritos anteriormente contienen toda esta información. En esta sección, sin embargo, se usan las observaciones entre enero de 2004 y diciembre de 2015 (se eliminan aquellas entre enero y marzo de 2016) con el fin de tener un panel balanceado en tiempo.

El mercado de pañales en Colombia se ha caracterizado por una competencia intensiva en estrategias de mercadeo, mejoras en calidad de productos y entrada y salida constante de marcas. La tabla 10 presenta cifras promedio anuales del período de participaciones de mercado, precios por unidad y segundos de publicidad por fabricante de pañales.

Tabla 10: Participación de mercado, precio promedio por unidad y volumen de publicidad por fabricante de pañales, promedios anuales 2004-2015

\begin{tabular}{lccc}
\hline Fabricante & $\begin{array}{c}\text { Participación de mercado } \\
\text { \% vol. total de ventas) }\end{array}$ & $\begin{array}{c}\text { Precio } \\
(\$ / \text { unidad })\end{array}$ & $\begin{array}{c}\text { Publicidad } \\
(\text { TRP seg., en miles })\end{array}$ \\
\hline Tecnosur & 41.93 & 506 & 381.50 \\
Kimberly & 23.22 & 671 & 139.19 \\
Familia & 25.58 & 512 & 237.04 \\
CMPC & 5.77 & 385 & 6.93 \\
Otros & 2.04 & 455 & 5.37 \\
Superercados & 1.46 & 369 & - \\
\hline
\end{tabular}

Fuente: Nielsen y OMD. Cálculos de los autores. 
Como se dijo en la sección 4.2, los datos usados para el presente análisis presentan una gran cantidad de ceros y datos faltantes. Uno de los hechos que explican esto es el constante cambio de nombre y de imagen en algunas marcas para mejorar su posición frente a las preferencias de los consumidores. En términos de los datos recolectados, esto generó dificultades para seguir la evolución de las marcas que cambiaron frecuentemente. Para solucionar este problema, se agregaron las ventas a nivel de tier, es decir, se eliminó la desagregación por etapas. Adicionalmente, de los diez productores que aparecían en la base original, se seleccionó una muestra de los seis más representativos en términos de participación de mercado por año, eliminando así las marcas con menor presencia y que constituían la fuente principal de datos faltantes o ceros en la base de datos. ${ }^{22}$ Finalmente, para capturar las preferencias de los consumidores por calidad, se definió una variedad de pañal o marca como una combinación entre el nombre comercial de la marca original y el tier al que corresponde el pañal comprado, lo que implica que en la base de datos, por ejemplo, el pañal Winny del tier 1 es considerada una variedad (tiene una identificación) distinta al pañal Winny del tier 4.

La base de datos final contiene entonces información sobre 19 variedades de pañal (marcatier), fabricadas por seis productores distintos, distribuidas hasta en seis regiones del territorio nacional $^{23}$ en 72 bimestres comprendidos entre 2004 y 2015.

Además de esta información, se complementó la base de datos final con información bimensual sobre el número total de segundos emitidos en publicidad en televisión provistas por la Agencia OMD. Así mismo, se determinó el tamaño del mercado potencial al que cada empresa tuvo acceso en cada año del período de estudio con proyecciones de población de 0 a 4 años basadas en el Censo de 2005 provenientes del Departamento Administrativo Nacional de Estadística (DANE).

\section{b) Identificación}

En Econometría se entiende que los parámetros están identificados cuando éstos se pueden estimar consistentemente a partir de un conjunto de observaciones. Si la identificación no se puede garantizar, los resultados no son ni estadística ni económicamente válidos así parezcan muy intuitivos. Con esto en mente, es importante señalar que uno de los problemas de identificación que comúnmente se presenta en los modelos de demanda está relacionado con la endogeneidad de los precios de los productos con las características no observadas de los productos, $\Delta \xi_{j t},{ }^{24}$ es decir, que las empresas pueden fijar los precios de sus productos en respuesta a los cambios en las preferencias de los consumidores en cada mercado local. Esto es un problema porque la ecuación (11) implica que la elección de cada consumidor está determinada por el precio del bien, pero dada la endogeneidad descrita anteriormente, los precios estarían determinados por los gustos de los consumidores, lo que conllevaría una doble implicación que impide estimar dicha ecuación.

Este problema se resuelve con la inclusión de variables instrumentales (en adelante, IV por la expresión en inglés instrumental variables), que son variables observadas no incluidas en el modelo de utilidad que se relacionan con la variable endógena pero no tienen ninguna correlación con las preferencias locales sobre el bien. Dada la definición de mercado en este

\footnotetext{
${ }^{22}$ CMPC, Kimberly, Papeles Nacionales, Procter and Gamble, Productos Familia y Tecnosur.

${ }^{23}$ No todas las marcas tuvieron presencia en todas las regiones del país.

${ }^{24}$ Para garantizar la estimación consistente de cualquier conjunto de parámetros de un modelo, se requiere como regla general la no correlación entre las variables regresoras observadas y el error del modelo.
} 
contexto (combinación región-bimestre), se utilizan los precios del mismo producto en las regiones distintas a la región que se va a instrumentar, como IV. La validez de estos precios como IV está determinada por dos factores: 1) los precios del mismo producto en otras regiones están relacionados con el precio local porque contienen información de los costos de producción que son comúnes para la misma marca independientemente de la región en la que se distribuya, y 2) estos precios de otras regiones no están correlacionados con las preferencias del mercado local porque una vez se controla por características del mercado local, las desviaciones locales en la valoración de las características no observables de los productos son independientes de las preferencias locales en otras zonas geográficas. ${ }^{25}$

\section{c) Estimación}

La estimación del modelo descrito previamente explota la estructura de panel de los datos (variación en variables observadas en un mismo período y variación entre períodos de tiempo) para controlar por efectos fijos de marca y tiempo (efectos estacionales y tendencias temporales). Esto garantiza que la demanda está identificada sin necesidad de imponer estructura sobre la oferta.

La estimación se basa en condiciones de momentos poblacionales $E\left[h(z)^{\prime} \rho\left(x, \theta_{o}\right)\right]=0$, en las que $z_{1}, \ldots, z_{M}$ cumplen el papel de variables exógenas utilizadas como isntrumentos; $\rho$ es una función de los parámetros del modelo y $\theta_{o}$ es el vector que contiene el verdadero valor de los parámetros. El estimador del método generalizado de los momentos se obtiene de resolver el siguiente problema de optimización:

$$
\min _{\theta} \rho(\theta)^{\prime} h(z) \hat{\Lambda}^{-1} h(z)^{\prime} \rho(\theta)
$$

donde $\hat{\Lambda}$ es un estimador consistente de $E\left[h(z)^{\prime} \rho \rho^{\prime} h(z)\right]$ y juega el rol de matriz de pesos óptima en la expresión (15).

De acuerdo con el modelo empírico descrito anteriormente, una vez se incluyen variables indicadoras (que toman el valor de 1 en caso de que la observación corresponda a la marca $j$ o cero en otro caso) por marca en el modelo, el término de error es $\Delta \xi_{j t}$, que se puede calcular como una función de las utilidades medias denotadas por $\delta_{j t}$ y que son funciones de las participaciones de mercado teóricas (o predichas en un lenguaje más técnico) dadas por la expresión (13), los datos y los parámetros. Siguiendo a Berry (1994), este cálculo requiere hallar primero una expresión para $\delta_{j t}$ del sistema de ecuaciones que resulta de igualar las participaciones de mercado observadas (las que se pueden calcular con base en los datos) y predichas:

$$
s_{j t}\left(x, p_{t}, \delta_{t} ; \sigma\right)=S_{j t}
$$

donde $s_{j t}(\cdot)$ denota la función que determina la participación de mercado definida en (13) y $S$ denota la participación de mercado observada en los datos. De la inversión de (16) se puede obtener una expresión para $\delta_{j t}$ como una función explícita de variables observables. Con todos estos elementos, el término de error en (15) se puede expresar como:

$$
\rho_{j t}=\delta_{j t}\left(x, p_{j t}, S_{j t} ; \sigma\right)-\left(\beta_{0}+x_{j} \beta_{1}-\alpha p_{j t}+\xi_{j}\right)
$$

\footnotetext{
${ }^{25}$ Este tipo de IV se conocen en la literatura como "Hausman Instruments" y son ampliamente utilizados para romper la endogeneidad de precios en modelos de demanda. Para más detalles sobre cómo funcionan, ver Hausman (1996) y Nevo (2001).
} 
Debido a que en este modelo no existe una solución analítica para el sistema en (16), la estimación de los parámetros se debe llevar a cabo mediante métodos numéricos y recursivos. Para una exposición detallada del método, ver Berry, Levinsohn and Pakes (1995), Nevo (2000a, 2001), y Knittel and Metaxoglou (2014).

\subsubsection{Resultados}

En esta sección se presentan los resultados estimación del modelo de demanda descrito en la sección 4.4.2 con base en los métodos expuestos anteriormente. A continuación, se presentan las estimaciones costos marginales y márgenes brutos de precio sobre costo marginal de producción por marca de la industria de pañales de acuerdo con la estructura de oferta que existe actualmente en la industria. Una vez estimados estos costos marginales, se procede a calcular precios y márgenes en escenarios hipotéticos que van desde una industria totalmente desconcentrada (cada empresa produce solamente una variedad de pañal) hasta la industria concentrada totalmente (un monopolio), pasando por estructuras de coordinación perfecta (o fusiones) entre algunas de las empresas de la industria. El objetivo de esta parte es mostrar cuáles serían los precios y márgenes de rentabilidad en la industria si las empresas pudieran fijar coordinadamente y de manera efectiva (es decir, sin posibilidad de desviaciones) la política de precios y los resultados del mercado, y contrastar esos resultados con las cifras que efectivamente presenta el mercado en el período de análisis (2004-2015).

a) Estimación de la demanda de pañales

La estimación del modelo de demanda se llevó a cabo bajo diferentes especificaciones del modelo, algunas más simplificadas y otras más flexibles, con el fin de seleccionar aquella que genera un mejor ajuste a los datos utilizados y el mercado de pañales y como una forma (estándar en la literatura) de chequear la robustez de los resultados y los efectos de incluir ciertos controles y efectos fijos sobre los parámetros de interés (en especial, el precio). La versión más flexible del modelo de demanda fue la descrita anteriormente. El modelo Logit mixto, también conocido en la literatura como modelo Logit con coeficientes aleatorios. Este modelo permite estimar una distribución de coeficientes para cada una de las variables en las que se incluyen coeficientes aleatorios, que miden valoraciones que varían de consumidor a consumidor (como se explicó anteriormente, los coeficientes son funciones de características demográficas no observadas). El modelo más restrictivo, conocido como modelo Logit multinomial (en este informe se hace referencia a éste como "Logit") es una versión simplificada del Logit mixto y permite estimar un parámetro por variable incluida que es común a todos los consumidores y mide la valoración promedio de toda una muestra de la población de una característica particular del bien.

Los resultados de la estimación de la demanda de pañales para el período 2004-2015 bajo diferentes especificaciones se presentan en la Tabla 11. En términos generales, los resultados son consistentes con la teoría económica: la relación estimada del precio con la cantidad demandada es negativa, lo que implica que un aumento en el precio de los pañales genera una disminución en la demanda. Los resultados del modelo Logit se presentan en las columnas (1) a (4), las dos primeras columnas presentan la estimación del modelo sin corregir por el problema de endogeneidad de los precios que se describió en la sección 4.4.3 mientras que las columnas (3) y (4) corrigen la endogeneidad. El objetivo es mostrar el efecto de incluir 
variables instrumentales para corregir por la endogeneidad del precio sobre la magnitud de los coeficientes estimados. En particular, el estimado del precio aumenta con la inclusión de IV, lo que implica que el problema de endogeneidad no solamente genera estimaciones inconsistentes sino que genera una subestimación del coeficiente del precio. Desde esta perspectiva, bajo el modelo Logit, las mejores estimaciones corresponden a las contenidas en las columnas (3) y (4).

Es de resaltar que a diferencia de los coeficientes del precio, los estimados de publicidad y la constante son de magnitudes similares en todas las regresiones del modelo Logit. Esto muestra robustez en los resultados y el hecho de que el problema de endogeneidad del precio solo afecta la estimación de este parámetro. Según esta especificación, la presencia de publicidad de pañales tiene un impacto medio positivo sobre la demanda del consumidor: mientras más gasten las empresas en la publicidad de sus productos en televisión, mayor será la valoración media que los individuos tendrán por los pañales desechables. Es importante notar que a pesar de que el efecto de la publicidad es estadísticamente significativo (es decir, estadísticamente distinto de cero), su magnitud es muy pequeña, lo que indicaría que la contribución de la publicidad a la decisión de un individuo sobre qué marca de pañal elegir es mucho menor que el impacto de los precios.

En la columna (5) se presentan los resultados de la estimación de la demanda de pañales según la especificación más flexible: la del modelo Logit mixto. Como se introdujo en la sección 4.4.2, se incluyeron coeficientes aleatorios para el precio y la constante del modelo de demanda. Dado que la inclusión de dichos coeficientes permiten estimar una distribución de efectos por individuo, los números de columna (5) muestran las medias de cada distribución y la columna siguiente, contiene la desviación estándar de dicha distribución de efectos con respecto a dicha media. En el caso de la publicidad no se incluyó un coeficiente aleatorio, por lo tanto, lo que el modelo permite capturar es el efecto medio (común para toda la población) y por esto la casilla de la desviación estándar está vacía.

Estos resultados muestran, en primer lugar, que el efecto medio del precio es más grande que el de los modelos Logit, lo que indica que la demanda es más sensible al precio (más elástica) que lo que arroja un modelo más restrictivo. Esta mayor sensibilidad es precisamente una ganancia aportada por una especificación más flexible que incluye efectos demográficos no observados. Precisamente, la importancia de incluir estos efectos heterogéneos entre individuos (en lugar de asumir que todos son iguales) se confirma con el hecho de que la estimación de la desviación estándar de la distribución de coeficientes de precio es significativa. Esto indica que las características demográficas no observadas tienen un poder importante para explicar cuán sensible son los individuos ante cambios en los precios de los pañales.

Es importante notar que en el caso del modelo Logit mixto, el efecto medio de la publicidad es negativo y aproximadamente -1, a diferencia de lo obtenido bajo la especificación más restrictiva. Esto implica que la publicidad tiene un efecto medio mayor en magnitud sobre la elección de los consumidores, pero de signo contrario a lo que captura el Logit. En este caso, un aumento en el tiempo de (y en el gasto en) publicidad en televisión genera una disminución del individuo en la valoración del producto. Esto parece contraintuitivo, sobre todo en una industria que ha mostrado competir intensamente en publicidad a través de los años y en la que la publicidad parece jugar un rol crucial en la construcción de reputación de marca y aumento de participación de mercado. Sin embargo, este efecto puede reflejar varias cosas en el contexto de un modelo flexible: por un lado, la inclusión de efectos heterogéneos entre individuos implica que hay algunos consumidores que valoran positivamente la publicidad 
y otros que no les gusta la publicidad y, en este caso, este último efecto puede ser el que domina en la estimación del efecto medio. Por otro lado, este modelo de utilidad puede estar subestimando el efecto de la publicidad debido a la forma simple como se incluye (de forma aditiva y lineal). En la literatura económica, la publicidad generalmente entra en los modelos de demanda de formas más complejas (mediante efectos dinámicos que tienen en cuenta el stock de publicidad acumulado en el tiempo, y no solo el flujo y mediante interacciones con variables que impactan directamente como el precio y las características del producto). Dado que el objetivo de esta modelación es estimar márgenes y costos marginales de las diferentes marcas de pañales, la publicidad se incluye de una manera simplificada y juega el papel de control en el modelo.

Tabla 11: Resultados de estimación de la demanda de pañales según diferentes especificaciones

\begin{tabular}{|c|c|c|c|c|c|c|}
\hline \multirow[b]{3}{*}{ Variable } & \multicolumn{4}{|c|}{ Logit } & \multicolumn{2}{|c|}{ Logit mixto } \\
\hline & \multicolumn{2}{|c|}{ OLS } & \multicolumn{2}{|c|}{ IV } & \multirow{2}{*}{$\begin{array}{c}\text { Medias } \\
(5)\end{array}$} & \multirow{2}{*}{$\begin{array}{c}\text { Desv. } \\
\text { estándar }\end{array}$} \\
\hline & (1) & $(2)$ & (3) & (4) & & \\
\hline Precio & $\begin{array}{c}-2.253 \\
(0.284)\end{array}$ & $\begin{array}{l}-2.096 \\
(0.251)\end{array}$ & $\begin{array}{l}-3.436 \\
(0.467)\end{array}$ & $\begin{array}{l}-3.008 \\
(0.414)\end{array}$ & $\begin{array}{l}-4.983 \\
(0.057)\end{array}$ & $\begin{array}{c}1.434 \\
(0.149)\end{array}$ \\
\hline Publicidad & $\begin{array}{c}0.036 \\
(0.017)\end{array}$ & $\begin{array}{c}0.033 \\
(0.016)\end{array}$ & $\begin{array}{c}0.042 \\
(0.017)\end{array}$ & $\begin{array}{c}0.037 \\
(0.016)\end{array}$ & $\begin{array}{l}-0.988 \\
(0.023)\end{array}$ & \\
\hline Constante & $\begin{array}{l}-4.745 \\
(0.347)\end{array}$ & $\begin{array}{l}-4.682 \\
(0.335)\end{array}$ & $\begin{array}{l}-4.225 \\
(0.384)\end{array}$ & $\begin{array}{l}-4.292 \\
(0.366)\end{array}$ & $\begin{array}{l}-0.126 \\
(0.068)\end{array}$ & $\begin{array}{c}2.077 \\
(0.041)\end{array}$ \\
\hline $\begin{array}{l}\text { Efectos fijos } \\
\text { Marca } \\
\text { Bimestre } \\
\text { Región }\end{array}$ & $\begin{array}{l}\sqrt{ } \\
\sqrt{ }\end{array}$ & $\begin{array}{l}\sqrt{ } \\
\sqrt{ } \\
\sqrt{ }\end{array}$ & $\begin{array}{l}\sqrt{ } \\
\sqrt{ }\end{array}$ & $\begin{array}{l}\sqrt{ } \\
\sqrt{ } \\
\sqrt{ }\end{array}$ & $\begin{array}{l}\sqrt{ } \\
\sqrt{ } \\
\sqrt{ }\end{array}$ & \\
\hline$R^{2}$ & 0.675 & 0.689 & 0.671 & 0.686 & - & \\
\hline Observaciones & 5,115 & 5,115 & 5,115 & 5,115 & 5,115 & \\
\hline
\end{tabular}

Notas: Las cifras en paréntesis corresponden a errores estándar asintóticamente robustos. En las columnas (3) y (4) se utilizaron precios del mismo producto en otras regiones como variables instrumentales ("IV"); en la columna (5) se utilizaron instrumentos óptimos.

Todos los parámetros estimados son estadísticamente significativos al $5 \%$ de niel de confianza.

4.4.5 ¿Se alcanzó el resultado colusivo en el mercado de pañales? Análisis estructural con base en modelos alternativos de oferta

Una vez se tienen los resultados de la demanda, se puede utilizar el modelo de oferta presentado en la sección 4.4.1 para recuperar los costos marginales y los márgenes de rentabilidad por marca subyacentes a los precios a los cuales se realizaron transacciones en el período de análisis.

La mediana de costos marginales de la distribución estimada en todo el período varía entre $\$ 106$ por pañal, correspondiente a la productora CMPC dueña de la marca Babysec, y $\$ 435$ por unidad, que corresponde a la firma con el precio mediano más alto del mercado Procter and Gamble y que produce la marca de pañales Pampers. Las tres empresas con 
mayor participación en la industria de pañales en Colombia presentan costos marginales de producción muy similares pero difieren en sus márgenes de rentabilidad y, consecuentemente, en sus precios de venta.

Con base en las estimaciones de costos marginales y los parámetros estimados de la función de demanda junto con las variables observadas en los datos, se pueden simular escenarios hipotéticos o contrafactuales que nos ayudan a determinar qué tan competitiva es la industria y cuál modelo de oferta explica mejor las cifras encontradas. En particular, se hace énfasis en los resultados que obtendría una de las empresas más importantes del mercado si lograra coordinarse de manera perfecta con otros de sus competidores para fijar precios y repartirse el mercado. Dicha coordinación perfecta solo sería posible bajo la integración horizontal (o fusión) de dichos competidores. Estos casos ilustran cómo cambiarían los precios y márgenes de rentabilidad de la empresa fusionada (o que conforma un cártel perfecto) con sus rivales, en comparación con la estructura real de la industria.

Como se describió en la sección 4.4.1, se exploran cuatro escenarios: uno en el que las 19 marcas incluidas en el modelo son producidas por empresas uniproducto distintas; otro en el que hay una fusión entre dos de las empresas líderes del mercado, Kimberly y Tecnosur; un tercero en el que hay una integración de las tres empresas con mayor participación de mercado, Kimberly, Tecnosur y Familia; y un último escenario en el que se supone que todas las marcas de la industria son producidas por un monopolista que maximiza sus beneficios como empresa multiproducto. La tabla 12 muestra los resultados medios para todas las empresas y todas las marcas. Los escenarios 1 y 4 constituyen modelos extremos a la estructura real de la industria, pero permiten determinar qué tan competitiva es esta industria. Los escenarios 2 y 3 suponen una integración entre empresas del sector, quienes siguen enfrentando competencia de empresas ajenas al acuerdo.

Como se muestra en la tabla 12, la industria de pañales desechables para bebé muestra resutados más cercanos a los que se obtendría en un contexto más competitivo (más empresas, produciendo solo una variedad de pañal) que a lo que obtendría un monopolista que domine completamente el mercado. En efecto, el precio mediano que fijaría una empresa en el escenario 1 es tan solo un 3,7\% menor que la cifra del escenario base obtenida de los datos observados. Esto contrasta con el precio del monopolista, que se incrementaría en un 45,1\% si una empresa lograra establecerse como la única del mercado. Los resultados en términos de márgenes de rentabilidad son similares: mientras que la diferencia entre lo que obtienen en promedio las empresas de la industria es un 3,3\% mayor a lo que se obtendría en una industria con más competidores, el margen que obtendría un monopolista por marca sería mayor en un $41,9 \%$ al que obtienen las empresas de la industria.

La primera conclusión que se puede extraer de estos resultados es la confirmación de lo que dice la teoría económica sobre márgenes de rentabilidad positivos y poder de mercado: el hecho de que las empresas de una industria obtengan márgenes positivos no indica que no estén compitiendo agresivamente sino que puede indicar que este es el resultado de la combinación entre una estructura de oferta que ofrece alternativas de buena calidad y la disposición a pagar de los consumidores por estos productos que valoran suficientemente como para pagar el precio al que éstos se ofrecen. Esta interpretación cobra aún más sentido si se tiene en cuenta que en el mercado hay tantas alternativas (diferentes marcas y calidades por marca) como para que la demanda reaccione de manera elástica a cambios en los precios. Esta evidencia constituye también un mensaje para las autoridades de la competencia: una industria competitiva no es aquella que alcanza el resultado extremo de rentabilidad cero; catalogar evidencia de márgenes 
positivos como resultado de prácticas anticompetitivas y castigarlas, puede distorsionar los incentivos de las empresas del sector y tener resultados devastadores para el bienestar de los consumidores.

Los resultados de los escenarios contrafactuales 2 y 3 muestran que bajo contextos de cartelización tanto precios como márgenes serían más altos que los obtenidos en el escenario base. En efecto, bajo el supuesto de una fusión entre Kimberly y Tecnosur (escenario 2), el precio mediano por unidad aumentaría en un $1,5 \%$ con respecto al precio del escenario base, precio que no es muy diferente al precio de base debido a que seguirían existiendo altas presiones competitivas de empresas rivales, pero que es suficiente para obtener un incremento en el margen de rentabilidad por marca de 9,5\%. El escenario 3 muestra cambios más drásticos dado que se trata de la integración entre los tres grandes productores de pañales del mercado. En este caso, el precio de la empresa "cartelizada" aumentaría casi en un $15 \%$ con respecto al precio mediano del escenario base, y el margen de rentabilidad por marca se incrementaría en casi un $24 \%$ (véase la tabla 12 ).

Tabla 12: Cambio porcentual de precios y márgenes de rentabilidad calculados bajo diferentes estructuras de oferta con respecto al escenario base

\begin{tabular}{lcc}
\hline Escenario & $\begin{array}{c}\text { Precios }^{a} \\
\left(\text { cambio \% }^{\circ}\right.\end{array}$ & $\begin{array}{c}\text { Márgenes }^{b} \\
\left(\text { cambio \%) }^{\circ}\right.\end{array}$ \\
\hline Base & $-3,7$ & - \\
1. Firmas uniproducto & 1,5 & $-3,3$ \\
2. Fusión Kimberly-Tecnosur & 14,3 & 23,5 \\
3. Fusión Kimberly-Tecnosur-Familia & 45,1 & 41,9 \\
4. Monopolio & & \\
\hline
\end{tabular}

Notas: Los cambios porcentuales se calculan como la diferencia entre la cifra contrafactual (escenario 1, 2, 3 o 4) y la cifra estimada en el escenario base, como proporción de la cifra base. Se usan las medianas de la distribución respectiva de 5115 observaciones (marca-regiónbimestre).

${ }^{a}$ Los precios de los escenarios hipotéticos se calculan con base en el precio observado y la estructura de oferta correspondiente.

${ }^{b}$ Los márgenes usados corresponden la rentabilidad bruta total de toda la cadena vertical (producción, transporte, venta) calculada como la diferencia entre el precio final que pagan los consumidores menos el costo marginal (estimado) de producción, esto es $(p-c m) / p$.

Por último, la tabla 13 muestra los resultados de los escenarios 2 y 3 comparados con el escenario base, teniendo solamente en cuenta los datos de las empresas involucradas en el presunto cártel (Kimberly, Tecnosur y Familia). Esta tabla busca ilustrar el caso de Kimberly (presunto instigador de la conducta investigada por la SIC). En el escenario base, se muestran las cifras observadas en el mercado y en los escenarios contrafactuales se calculan los incrementos que ésta empresa hubiera podido obtener si en cada caso hubiera podido alcanzar un control absoluto de su(s) competidor(es) de tal manera que sus políticas de precios fueran determinadas centralizadamente como una empresa multiproducto dueña de las marcas de sus antiguos competidores (Huggies y Winny en el escenario 2, y Huggies, Winny y Pequeñín en el escenario 3), sin enfrentarse al riesgo de una desviación por parte de alguna de las empresas 
bajo su control. ${ }^{26}$

Como lo muestran los resultados, la empresa fusionada bajo el escenario 2 hubiera logrado incrementar su precio y márgen medianos en un $4,8 \%$ y $3,2 \%$ respectivamente con un acuerdo con Tecnosur que se reflejara en el control de precios deseado en el mercado. Con una integración con Tecnosur y familia, por su parte, la firma instigadora hubiera podido lograr un incremento en precios de $15 \%$ y un aumento en márgenes de rentabilidad por marca de una cifra similar. Estos porcentajes, que en términos agregados hubieran representado un aumento millonario en las ganancias de la empresa fusionada, indican claramente que los integrantes del acuerdo no estuvieron alineados con los objetivos de la instigadora puesto que sus resultados difieren de los obtenidos en el escenario colusivo 3. En otras palabras, las cifras permiten probar que de haberse dado un acuerdo, hubo fallas de coordinación, o hubo decisiones de una o más empresas contrarias al acuerdo, o hubo fallas en la verificación por parte de la empresa instigadora que permitió a las demás empresas desviarse del acuerdo buscando su propio beneficio, puesto que el resultado que se hubiera alcanzado con una coordinación perfecta (similar a una fusión) no se alcanzó.

Tabla 13: Cambio porcentual en precios y márgenes de rentabilidad para el caso de Kimberly, escenarios colusivos

\begin{tabular}{lcc}
\hline Escenario & $\begin{array}{c}\text { Precio }^{a} \\
\text { (cambio \%) }^{2}\end{array}$ & $\begin{array}{c}\text { Márgen }^{b} \\
(\text { cambio \%) }\end{array}$ \\
\hline Kimberly (escenario base) & & - \\
2. Fusión Kimberly-Tecnosur & $4.8 \%$ & $3.2 \%$ \\
3. Fusión Kimberly-Tecnosur-Familia & $15.0 \%$ & $14.7 \%$ \\
\hline
\end{tabular}

Notas: Los cambios porcentuales se calculan como la diferencia entre la cifra contrafactual (escenario 1, 2, 3 o 4) y la cifra estimada en el escenario base, como proporción de la cifra base. Se usan las medianas de la distribución respectiva de 5115 observaciones (marca-regiónbimestre).

${ }^{a}$ Los precios de los escenarios hipotéticos se calculan con base en el precio observado y la estructura de oferta correspondiente.

${ }^{b}$ Los márgenes usados corresponden la rentabilidad bruta total de toda la cadena vertical (producción, transporte, venta) calculada como la diferencia entre el precio final que pagan los consumidores menos el costo marginal (estimado) de producción, esto es $(p-c m) / p$.

\section{Conclusiones}

Este artículo tiene como propósito mostrar que existen herramientas cuantitativas desarrolladas por la literatura económica que resultan muy útiles a las autoridades de la competencia para llevar a cabo estudios de mercado que les permitan tener un panorama completo de los

\footnotetext{
${ }^{26}$ Esta descripción corresponde a una fusión en el que la empresa adquirida pasa a ser una filial de la matriz más que un socio de un cártel que sigue tomando decisiones con base en su propia función objetivo y que tiene altas posibilidades de desviarse del acuerdo. La razón por la que se supuso una fusión y no un simple acuerdo es porque la fusión ilustra las cifras máximas que una empresa puede obtener sobre cualquier otro acuerdo horizontal y porque de esta manera se evita lidiar con las complicaciones de un modelo de colusión explícita en la que los acuerdos pueden llegar a ser difíciles de sostener por la probabilidad de que algún integrante del cártel se desvíe del acuerdo. Estos resultados muestran entonces lo que se denominaría colusión perfecta entre las firmas involucradas.
} 
efectos de un cartel en el mercado. Con una aplicación "Caso pañales", se muestra que a pesar de la contundnete evidencia encontrada por la SIC sobre la existencia del cartel, las fallas de coordinación entre las empresas (bien sea porque los integrantes del acuerdo no estuvieron alineados con los objetivos del cartel o porque las empresas tomaron decisones guiados por intereses particulares), lo cual llevó a resultados de mercado diferentes a los de un mercado coludido, que sugieren que la multa impuesta por la SIC no responde a criterios de impacto en el mercado siendo ésta demasiado alta.

El análisis de series de tiempo de los precios arroja evidencia mixta por lo que no es posible concluir que existe un efecto en el mercado derivado de conductas restrictivas de la competencia sin agregar al análisis posibles presiones de oferta y demanda que pueden explicar los patrones observados dichas series. Adicionalmente, se mostró que no existe evidencia empírica que muestre un cambio estructural en la variabilidad de los precios en ninguno de los segmentos analizados al comparar el período colusivo con el período postcolusión. Por ende, no parece cumplirse una de las predicciones teóricas fundamentales discutida desde Stigler (1964) y comúnmente adoptada por las autoridades de competencia en el mundo, según la cual después de detectada la colusión, los precios tienden a caer abruptamente generando un cambio estructural en las series. Finalmente, dada la evidencia estadística se podría pensar que la cartelización de las empresas en el mercado de pañales desechables para bebé en Colombia, no parece haber tenido los efectos esperados sobre el mercado y, en particular, sobre los precios.

El segundo ejercicio arroja resultados que son consistentes con los hallazgos anteriormente descritos: las cifras del mercado están lejos de lo que debió observarse si el acuerdo colusivo se hubiera ejecutado exitosamente en la práctica (es decir, bajo coordinación perfecta). En efecto, este análisis muestra que el mercado, con su estructura de oferta actual, presenta resultados que se acercan más a un referente competitivo que a los resultados que obtendrían empresas con alto poder y dominio del mercado. Además, al comparar los resultados observados en el mercado con los que se obtendrían en casos de colusión perfecta entre las empresas investigadas, se muestra que la diferencia en las cifras muestran que se estuvo lejos de alcanzar el resultado colusivo. Esto muestra que lo más factible es que los integrantes del acuerdo no estuvieron alineados con los objetivos del cartel, puesto que sus resultados difieren de los obtenidos en el escenario de coordinación perfecta. Las cifras obtenidas mediante este ejercicio permiten intuir que hubo fallas de coordinación o verificación por parte de la empresa instigadora que permitió a las demás empresas desviarse del acuerdo buscando su propio beneficio.

La evidencia empírica obtenida en este artículo es consistente con la la teoría y la experiencia internacional. No es posible probar ni la existencia ni los efectos de un acuerdo colusivo con base en el estudio de series de precios, pues existen muchas variables económicas que pueden determinar la estabilidad observada en los precios, una tendencia continua al alza, o un comportamiento paralelo en los precios de empresas rivales. Por esto, a menudo este tipo de análisis conduce a resultados erróneos, ambigüos o distintos a lo que se quiere probar. En todo caso, un análisis de precios no constituye prueba suficiente de colusión. La literatura económica ha desarrollado métodos que combinan la teoría con la econometría y permiten obtener un diagnóstico más preciso y creíble sobre la existencia y el alcance de un acuerdo colusivo, que además permiten cuantificar sus efectos. Es por esto que un análisis econométrico de tipo estructural se constituye como una herramienta de gran utilidad para las autoridades de competencia en su búsqueda de encontrar el verdadero impacto de de las 
conductas investigadas.

\section{Bibliografía}

1. Abrantes-Metz, R. M., L. M. Froeb, J. Geweke and C. T. Taylor (2006), "A Variance Screen for Collusion", International Journal of Industrial Organization, No. 24, pp. 467-486.

2. Abreu, D. (1988), "On the theory of infinitely repeated games with discounting", Econometrica, Vol. 56, pp. 383-396.

3. Athey, S., Bagwell, K., Sanchirico, C., 2004. "Collusion and price rigidity", Review of Economic Studies Vol. 71, No. 2, pp. 317-349

4. Bejger, S., (2010), "Econometric tools for detection of collusion equilibrium in the industry", Dynamic Econometric Models, Vol. X, pp.34-45.

5. Berry, Steven (1994), "Estimating discrete-choice models of product differentiation", The RAND Journal of Economics, Vol. 25, No. 2, pp. 242-262.

6. Berry, Steven, Levinsohn, James and Pakes, Ariel (1995), "Automobile prices in market equilibrium", Econometrica, Vol. 63, No. 4, pp. 841-890.

7. Blanckenburg, K. V. and A. Geist (2009), "How can a Cartel be Detected?" International Advances in Economic Research, 15, 421-436.

8. Blanckenburg, K. V. and A. Geist (2013), "Detecting Illegal Activities: The Case of Cartels", European Journal of Law and Economics, Vol. 32, pp. 15-33.

9. Bajari, P. and L. Ye (2003), "Detecting Collusion in Procurement Auctions", Review of Economics and Statistics, Vol. 85, pp. 971-989.

10. Bolotova, Y., J. M. Connor and D. J. Miller (2008), "The Impact of Collusion on Price Behavior: Empirical Results from Two Recent Cases", International Journal of Industrial Organization, No. 26, 1290-1307.

11. Carlson, J. and R. McAfee (1983), "Discrete Equilibrium Price Dispersion", Journal of Political Economy, Vol. 91, pp. 480-493.

12. Carlton, D. W. (1986), "The Rigidity of Prices", American Economic Review, Vol. 76, pp. 637-658.

13. Compte, O., Jenny F. y Rey, P. (2002), "Communication in Repeated Games with Imperfect Privite Monitoring", Econometrica, Vol. 66, pp. 597-626.

14. Connor, J. M. (2004), "Collusion and Price Dispersion", Staff Paper, 04-14, Department of Agricultural Economics, Purdue University.

15. Connor, J. M. (2005), "Collusion and Price Dispersion", Applied Economics Letters, Vol. 12, pp. 335-338. 
16. Chamberlain, E. (1929). "Duopoly: Value Where Sellers Are Few", Quarterly Journal of Economics Vol. 43, pp. 63-100.

17. Ellison, G. (1994), "Theories of Cartel Stability and the Joint Executive Committee", RAND Journal of Economics, Vol. 25, No.1, pp. 37-57.

18. Evans W. y Kessides I. (1994), "Living by the golden rule: Multimarket contact in the U.S. Airline Industry", Quarterly Journal of Economics, Vol. 109, pp. 341-366.

19. Feinstein, J., Block, M., Nold, F., (1985). "Asymmetric information and collusive behavior in auction markets". American Economic Review, Vol. 75, No.3, pp. 441-460.

20. Green, E. J and R. H. Porter (1984), "Noncooperative Collusion under Imperfect Price Information", Econometrica, Vol. 52, pp. 87-100.

21. Genesove, D. Mullin, W., (2001). "Rules, communication and collusion: narrative evidence from the sugar institute case". American Economic Review, Vol. 91, No.3, pp. 379-398.

22. Haltinwanger, J. and J. E. Harrington (1991), "The Impact of Cyclical Demand Movements on Collusive Behavior",RAND Journal of Economics, Vol. 22, pp. 89-106.

23. Harrington, J. (2008), "Detecting Cartels", Handbook in Antitrust Economics, Paolo Buccirossi, editor (MIT Press).

24. Harrington, J. (2005), "Optimal Cartel Pricing in the Presence of an Antitrust Authority", International Economic Review, Vol. 46, pp. 145-169.

25. Harrington, J. y Chen, J. (2006). "Cartel pricing dynamics with cost variability and endogenous buyer detection", International Journal of Industrial Organization, Vol. 24, pp. $1185 ? 1212$.

26. Hausman, Jerry (1996), "Valuation of new goods under perfect and imperfect competitio", The Economics of New Goods, Studies in Income and Wealth, Vol. 58, ed. by T. Bresnahan and R. Gordon, National Bueau of Economic Research, Chicago.

27. LaCasse, C., (1995). "Bid rigging and the threat of government prosecution". RAND Journal of Economics, No. 26 (3), pp. 398-417.

28. Lande, R., and Marvel, H. (2000), "The Three Types of Collusion: Fixing Prices, Rivals, and Rules", Wis. L. Rev, Vol. 941, pp. 945-46.

29. Knittel, Christopher and Metaxoglou, Konstantinos (2014), "Estimation of random coefficient demand models: two empiricists' perspective", Review of Economics and Statistics, Vol. 96, No. 1, pp. 34-59.

30. Kuhn K., and Motta M. (1999), "The Economics of Joint Dominance", Unpublished Manuscript.

31. Markovits, R. S. (2016), "Economics and the Interpretation and Application of US and EU Antitrust Law. A Summary" ,The Antitrust Bulletin, Vol. 61, pp. 3-83. 
32. Maskin, E., and Tirole, J. (1988), "A theory of dynamic oligopoly, II: Price competition, kinked demand curves, and Edgeworth cycles", Econometrica, pp. 571-599.

33. Motta M. (2004), "Competition Policy Theory and Practice", New York, Cambridge University Press.

34. Nevo, Aviv (2000a), "A practitioner's guide to estimation of random-coefficients Logit models of demand", Journal of Economics and Management Strategy, Vol. 9, No. 4, pp. 513-548.

35. (2000b), "Mergers with differentiated products: the case of the ready-to-eat cereal industry", RAND Journal of Economics, Vol. 31, No. 3, pp. 395-421.

36. (2001), "Measuring market power in the ready-to-eat cereal industry", Econometrica, Vol. 69, No. 2, pp. 307-342.

37. Parker P. y Roller L. (1997), "Collusive conduct in duopolies: Multimarket contact and cross-ownership in the mobile telephone industry", Rand Journal of Economics, Vol. 28, pp. 304-322.

38. Raith M. (1996), "A General Model of Information Sharing in Oligopoly", Journal of Economic Theory, Vol. 71, pp. 260-288.

39. Rey, P., and Tirole, J. (2013), "Cooperation vs. collusion: how essentiality shapes co-opetition", IDEI Working Papers, No. 801.

40. Rotemberg, J. J. and G. Saloner (1986), "A Supergame-Theoretic Model of Price Wars during Booms", American Economic Review, Vol. 76, pp. 390-407.

41. Stigler, G. (1964), "A Theory of Oligopoly", Journal of Political Economy, Vol. 72, pp. 44-61.

42. Superintendencia de Industria y Comercio (2014), Resolución 47965 del 4 de agosto de 2014.

43. Superintendencia de Industria y Comercio (2016), Informe Motivado 13-266923, "Caso Pañales".

44. Superintendencia de Industria y Comercio (2016), Resolución 31739 del 26 de mayo de 2016. 